Research Article

\title{
Electromagnetic Bridge Energy Harvester Utilizing Bridge's Vibrations and Ambient Wind for Wireless Sensor Node Application
}

\author{
Farid Ullah Khan (iD) and Muhammad Iqbal \\ Institute of Mechatronics Engineering, University of Engineering and Technology, Peshawar, Pakistan \\ Correspondence should be addressed to Farid Ullah Khan; dr_farid_khan@uetpeshawar.edu.pk
}

Received 29 April 2017; Revised 10 October 2017; Accepted 8 November 2017; Published 4 February 2018

Academic Editor: Jesus Corres

Copyright ( 2018 Farid Ullah Khan and Muhammad Iqbal. This is an open access article distributed under the Creative Commons Attribution License, which permits unrestricted use, distribution, and reproduction in any medium, provided the original work is properly cited.

\begin{abstract}
This paper presents novel electromagnetic bridge energy harvesters (BEHs) utilizing bridge vibrations and ambient wind surges to power wireless sensor nodes used for bridges' health monitoring. The developed BEHs are cantilever-type and are comprised of a wound coil, permanent magnet, an airfoil, cantilever beam, and a support. Harvesters are characterized in-lab under different vibration levels and are subjected to variable speed air surges. The harvesters exhibit multiresonant frequencies; prototype I has resonant frequencies of 3.6, 14.9, and $17.6 \mathrm{~Hz}$. However, 7.6, 33, and $45 \mathrm{~Hz}$ are the resonant frequencies for prototype II. Under vibration testing, prototype I produced a maximum voltage of $206 \mathrm{mV}$ and an optimum power of $354.51 \mu \mathrm{W}$ at a frequency of $3.6 \mathrm{~Hz}$ and $0.4 \mathrm{~g}$ acceleration. However, at a frequency of $7.6 \mathrm{~Hz}$ and $0.6 \mathrm{~g}$ acceleration, prototype II showed the capability of generating a maximum voltage of $430 \mathrm{mV}$ and an optimum power of $2214.32 \mu \mathrm{W}$. Moreover, when BEHs are characterized under variable speed air surges, prototype I generated a load voltage of $19 \mathrm{mV}$ and a power of $7.84 \mu \mathrm{W}$ at an air speed of $9 \mathrm{~m} / \mathrm{s}$; however, $22 \mathrm{mV}$ and $9.14 \mu \mathrm{W}$ load voltage and power, respectively, are developed by prototype II at $6 \mathrm{~m} / \mathrm{s}$ air speed.
\end{abstract}

\section{Introduction}

Energy harvesting from ambient vibration is a nondestructive and maintenance-free solution for powering remote, integrated, abandoned, and embedded sensing systems used for health monitoring of machines (such as reciprocating engines, compressors, pumps, turbines, electrical generators, and motors) and civil structures (such as bridges, flyovers, and high risers). In civil infrastructure, health monitoring is significant to avoid catastrophic failure, to save human lives, and also to alleviate detours and traffic nonuniformities [1]. In reality, due to environmental hazards, fatigue, improper usage, material aging, and earthquakes, the condition of civil infrastructure continues to degrade with the passage of time [2]. For deterioration, damage recognition, and risk investigation, wireless sensor node- (WSN-) based health monitoring systems are normally used to interrogate continuously and remotely the condition of bridges [3]. The schematic of a typical WSN is shown in Figure 1. For bridge's health monitoring, either accelerometer or strain sensor is used to provide the real-time signals of bridge's vibration or strain levels. The sensor's signals are processed (for analog to digital conversion, noise filtration, and amplification) with condition and processing part of the WSN. The processed data is then supplied to the transceiver and to the on-board memory. The power management part on the WSN is responsible for the power distribution from the power source (battery or super capacitor) to all the components on the WSN platform. The programmable microcontroller manages all the activities (sleep mode, measuring mode, and transmission mode) which are programmed for the WSN.

Usually, WSNs deployed for health monitoring require batteries for their operation. However, batteries are of limited life span and have to be either replaced or recharged repeatedly which makes WSNs prohibitively inconvenient and in some cases, expensive. Additionally, interrupted 


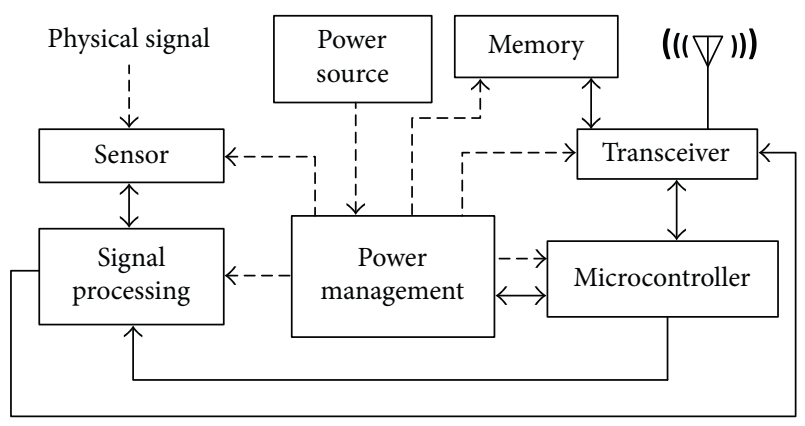

Figure 1: Schematic diagram of a wireless sensor node.

functionality (due to lack of battery power) of a WSN is a burden on the network and may result in network congestion. Although during operational mode, the power need of commercial ultralow power MEMS sensors is in the range of 1.8 to $324 \mu \mathrm{W}$ for a continuous current supply of 1.7 to $2.5 \mu \mathrm{A}$ [4] only. However, in WSNs, more power is required for data transmission $(0.09$ to $128 \mathrm{~mW})$ [5] rather than sensing. Furthermore, due to the rapid developments in low power sensors, microcontrollers, conditioning circuits [6], power management circuits [7], and transmission module and because of efficient wireless sensor networks [8], the power requirement of WSNs is on a sharp decline. The energy harvesting technique [9-13] that is developed two decades ago has the tendency and capability to power these low power WSNs [14]. The energies, those are present in bridge's environment and can be taken into the account for energy harvesting, are vibration (vehicle-induced vibrations), acoustic (vehicle noise), wind (naturally blowing wind and air surges produced due to vehicle motion), and solar. However, bridge's vibration [15-17] and ambient wind [18] are more reliable to be utilized for the harvesting energy on bridges.

Usually, the traffic and wind-induced bridge's vibrations exhibit low frequency and low acceleration amplitude. The vibration data of various bridges is summarized in Table 1. The maximum acceleration of bridge vibration reported by Sazonov et al. [19] is $0.55 \mathrm{~g}$; however, the maximum frequency $(40 \mathrm{~Hz})$ is recoded for the bridge reported by [20]. Short and medium span bridges vibrate with frequency typically ranging from 2 to $8 \mathrm{~Hz}$ and acceleration levels less than $0.1 \mathrm{~g}$ [21]. Some bridges exhibit random vibrations with low frequency ( 2 to $30 \mathrm{~Hz}$ ) and low excitations of 0.01 to $0.05 \mathrm{~g}$ [22]. However, at other bridge structures, the vibrations are comparatively more severe with a frequency range of 1 to $5 \mathrm{~Hz}$ and acceleration levels from 0.3 to $1.5 \mathrm{~g}$. From Table 1 , it can be seen that in the bridges' vibrations, the overall frequency content actually ranges from 0 to $40 \mathrm{~Hz}$ and the overall acceleration level is from 0 to $0.55 \mathrm{~g}$.

The bridges' vibration levels provided in Table 1 are quite enough to drive the vibration-based energy harvesters $[41,42]$ to produce electrical power for the operation of WSNs mounted for the heath monitoring of bridges. In vibration-based energy harvesters, there has been a substantial research and development and to extract the bridge's excitations, vibration-based piezoelectric [43],
TABLE 1: Bridges' vibration data.

\begin{tabular}{|c|c|c|c|}
\hline Bridge & $\begin{array}{c}\text { Frequency } \\
(\mathrm{Hz})\end{array}$ & $\begin{array}{l}\text { Acceleration } \\
(g)\end{array}$ & Ref. \\
\hline RT11 (New York, USA) & 1 & 0.55 & [19] \\
\hline Ferrite (Sweden) & $14-15$ & 0.02 & [20] \\
\hline Barrel Springs & 3.003 & 0.09 & [21] \\
\hline Grove Street (Michigan, USA) & $2-30$ & $0.01-0.035$ & {$[22]$} \\
\hline - & $2-8$ & 0.1 & [23] \\
\hline New Arsta (Sweden) & $1-5$ & $0.3-1.5$ & {$[24]$} \\
\hline Komtur (Berlin) & $2-2.6$ & $0-0.006$ & [25] \\
\hline $\begin{array}{l}\text { New Carquinez } \\
\text { (California, USA) }\end{array}$ & $2-30$ & $0.01-0.13$ & [26] \\
\hline (North, France) & 2 & 0.05 & [27] \\
\hline NC (USA) & $1-40$ & $0.01-0.1$ & [28] \\
\hline $\begin{array}{l}\text { Huanghe cable-stayed bridge } \\
\text { (China) }\end{array}$ & $1-2$ & 0.015 & [29] \\
\hline $\begin{array}{l}\text { Golden Gate } \\
\text { (San Francisco, USA) }\end{array}$ & $0-1.5$ & $0-0.061$ & {$[30]$} \\
\hline $\begin{array}{l}\text { IH-35N over Medina River } \\
\text { (Texas) }\end{array}$ & 3.1 & 0.15 & {$[31]$} \\
\hline California (USA) & $10-20$ & 0.0002 & {$[32]$} \\
\hline Box girder (Austin, USA) & $1-15$ & 0.12 & [33] \\
\hline Iwate Prefecture (Japan) & $0-25$ & 0.005 & [34] \\
\hline Ypsilanti (Michigan, USA) & $2-30$ & $0.01-0.035$ & [35] \\
\hline $\begin{array}{l}\text { Seohae Grand Bridge } \\
\text { (South Korea) }\end{array}$ & 1 & 0.0125 & [36] \\
\hline Voigt bridge & 4.8 & 0.0025 & [37] \\
\hline Seohae Grand (South Korea) & 1 & 0.02 & [38] \\
\hline Iriri & - & 0.278 & [39] \\
\hline Ferrite (Sweden) & 4.1 & 0.02 & {$[40]$} \\
\hline
\end{tabular}

electromagnetic [44-46], and electrostatic [47, 48] energy harvesters can be utilized. Vibration-based piezoelectric energy harvester usually consists of a piezoelectric membrane or beam. When the harvester is exposed to base excitation, the membrane or beam also starts oscillations and deformation or strain is produced in the piezoelectric material. That strain actually induces the voltage (polarization) in the piezoelectric material [49-51]. Electromagnetic energy harvester comprised of a beam, coil, magnet, and base support. When the harvester is excited, the beam starts vibrating and the magnet attached to the beam also starts moving relative to the coil, and due to the changing magnetic flux, a voltage is induced in the coil [52-54]. However, electrostatic energy harvester is made of two conductive plates which are parallel to each other. The plates are separated by vacuum or air and initially, an electric field is provided between the plates (with the help of a battery). When external vibration is applied to an electrostatic energy harvester, the plates of charged capacitor separate and the mechanical energy is converted into electrical energy $[55,56]$.

For the health monitoring system of bridge structures, several BEHs are devised and reported in the literature. The reported $\mathrm{BEHs}$ are mainly either electromagnetic type or piezoelectric type. An electromagnetic $\mathrm{BEH}$ [19] produced with 
wound coil, permanent magnets, and spring has a resonant frequency of $3.1 \mathrm{~Hz}$. It is reported to generate $10 \mathrm{~V}$ voltage and $1000 \mu \mathrm{W}$ power at $3 \mathrm{~mm}$ displacement and $3.1 \mathrm{~Hz}$ frequency. Moreover, a power development of $12500 \mu \mathrm{W}$ is also reported when the energy harvester is subjected to $10 \mathrm{~mm}$ displacement amplitude and resonant frequency.

In BEH [33], a rod having a number of cylindrical magnets is enclosed in a nylon casing and is allowed to oscillate vertically (with the aid of the end repulsive magnets located in the end caps) to generate energy from vibrations. Various parts (such as caps, frame, and casing) of the BEH are fabricated with rapid prototyping machine. When tested under sinusoidal excitation, the harvester is reported to produce a maximum power of $26 \mathrm{~mW}$ at $0.08 \mathrm{~g}$ and $2.2 \mathrm{~Hz}$.

Neodymium magnets, wound coil, and a pipe (acrylic) are used to develop an electromagnetic BEH [36]. End magnets in the outer caps are utilized to help the moving magnets to levitate in the pipe (having the wound coil) during operation. When mounted on the bridge structure, the developed $\mathrm{BEH}$ generated $10 \mathrm{mV}$ voltage and $2 \mu \mathrm{W}$ power from the excitations at $8 \mathrm{mg}$ acceleration and frequency of $14 \mathrm{~Hz}$.

A rod (steel) having stacked magnets and core (steel) discs is kept stationary while wound coils attached to helical springs are allowed to vibrate in response to external oscillation in BEH developed by [40]. A voltage and power production of $0.71 \mathrm{~V}$ and $0.12 \mathrm{~mW}$, respectively, is obtained from the developed $\mathrm{BEH}$ when vibrated at a frequency of $4.1 \mathrm{~Hz}$ and base acceleration of $25 \mathrm{mg}$.

An electromagnetic BEH comprised of permanent magnet, wound coil, and microfabricated planar spring is reported for low frequency vibration applications [57]. For the developed harvester, a power generation of $163 \mu \mathrm{W}$ (at load resistance $=220 \Omega$ ) is reported at $10 \mathrm{~Hz}$ frequency and $1 g$ base acceleration.

Membrane (latex), wound coils, PCB-planar coils, neodymium magnets, and spacers (Teflon) are used to develop a $\mathrm{BEH}$ [58]. In the harvester, the magnets are placed on the membrane and are allowed to oscillate; however, the wound coils and planar coils are all kept fixed. Under sinusoidal excitation at $27 \mathrm{~Hz}$ and $3 \mathrm{~g}$, single wound coil is reported to produce $11.05 \mathrm{mV}$ voltage and $2.1 \mu \mathrm{W}$ power; however, under same operation condition, a power of $1.8 \mu \mathrm{W}$ and voltage of $15.5 \mathrm{mV}$ are generated by a single planar coil.

A piezoelectric cantilever-type $\mathrm{BEH}$ [25] comprised three cantilever beams. Frequency upconversion technique is utilized for the harvester's operation. In the harvester, the main beam has a proof mass at the free tip; moreover, two beams (piezoelectric bimorph) are located on top of the main beam just above the proof mass. The frequency of the main beam is kept low $(2 \mathrm{~Hz})$; however, the resonant frequencies of the piezoelectric beams are comparatively high. During operation when the proof mass hit the stopper, it excites the piezoelectric beams which then vibrate relative at higher frequencies. For the single piezoelectric beam, a load power of $64 \mu \mathrm{W}$ (at $70 \mathrm{k} \Omega$ optimum load) at $2 \mathrm{~Hz}$ and $0.1 \mathrm{~g}$ vibration is reported.

A piezoelectric cantilever-type BEH [27] is devised for narrow band vibrations. In the harvester, two piezoelectric patches are bonded (near the clamped end of the beam) to the top and bottom surfaces of the steel cantilever beam; however, a proof mass is bonded to the free end of the beam to tune the BEH at the resonant frequency of $14.5 \mathrm{~Hz}$. When tested at the bridge's real vibration in which the frequency content is less than $15 \mathrm{~Hz}$, the $\mathrm{BEH}$ is reported for the voltage generation of 1.8 to $3.6 \mathrm{~V}$ and a power production of $30 \mu \mathrm{W}$.

A cantilever-type piezoelectric BEH [59] is developed with tunable capability. A couple of helical springs is attached in between the proof mass (at beam tip) and frame (at beam fixed end) to keep the piezoelectric cantilever beam in compression. The preload technique is utilized to tune the piezoelectric beam. The screws provided in the frame are used to set the preload on the beam. The harvester exhibits the frequencies $44.5 \mathrm{~Hz}$ and $40 \mathrm{~Hz}$ at preload of $2 \mathrm{~N}$ and $4 \mathrm{~N}$, respectively, and it is reported to generate a load voltage of 27 and $28 \mathrm{~V}$ when connected to a load of $10 \mathrm{M} \Omega$ and vibrated at $1 \mathrm{~g}$.

For low frequency operation, a cantilever-type BEH [59] is produced. Multi-impact phenomenon and frequency upconversion technique are utilized for the basic working of the harvester. In the $\mathrm{BEH}$, there are two vertically oriented piezoelectric contained cantilever beams. Moreover, protruding knobs are made on the free end of piezoelectric beams. In between the piezoelectric beams, a proof mass having rollers is suspended with the help of a coil spring. The resonant frequency of the spring-mass component is kept low $(2.71 \mathrm{~Hz})$; however, the resonant frequencies of the beams are relatively high $(120 \mathrm{~Hz})$. During operation, due to vertical vibration of the proof mass, the sudden impact of the roller beams' knobs causes the piezoelectric beams to vibrate horizontally at its own resonant frequency. When the devised BEH is applied to the sinusoidal vibration, it generated a mean load power of $7.7 \mathrm{~mW}$ (at optimum load $=9.7 \mathrm{k} \Omega$ ) and average power of $9.4 \mathrm{~mW}$ at $0.29 \mathrm{~g}$ and $4.4 \mathrm{~g}$, respectively. Moreover, under simulated bridge's oscillations, the harvester delivered $2.8 \mathrm{~mW}$ mean power to the optimum load.

Cantilever-type piezoelectric BEHs [59] used piezoelectric bimorph material to extract the energy for bridge's health monitoring system. Three prototypes are reported in this work. Prototype I which has a resonant frequency of $117.1 \mathrm{~Hz}$ is a bimorph cantilever beam having no proof mass. In prototype II, proof mass is added due to which its resonant frequency is lowered down to $65.2 \mathrm{~Hz}$. However, to extract the energy from the comparatively broader band of excitation an array type, prototype III is developed that have six piezoelectric beams. The beams in prototype III are tuned to frequencies of $63.25,76.63,71.5,66.25,63.13,58.88$, and $55.38 \mathrm{~Hz}$. Under optimum load condition, prototype I and prototype II are reported to generate power levels of $197 \mu \mathrm{W}$ (at $11.8 \mathrm{k} \Omega$ ) and $657 \mu \mathrm{W}$ (at $14.9 \mathrm{k} \Omega$ ), respectively, at $0.21 \mathrm{~g}$ acceleration. Moreover, for prototype III, an aggregate power production of $1.73 \mathrm{~mW}$ is also reported when it is subjected to $0.2 \mathrm{~g}$ acceleration excitation.

A piezoelectric $\mathrm{BEH}[60]$ is devised to extract the energy from the bridge's bearing vibrations. Six $2 \mathrm{~mm}$ thick piezoelectric plates are adhesively bonded to the steel plate with conductive epoxy to form a composite sheet. By sandwiching rubber layers in between five composite sheets, the reported $\mathrm{BEH}$ is developed. Under a dynamic load of $17.8 \mathrm{kN}$ amplitude and $2 \mathrm{~Hz}$ frequency, the harvester is reported to generate 
$650 \mathrm{mV}$ voltage. Moreover, at a forcing frequency of $1.5 \mathrm{~Hz}$, the energy harvester delivered a power of $83.5 \mu \mathrm{W}$ to the optimum load of $480 \Omega$.

Two linear and one nonlinear piezoelectric BEHs [61] are produced with the same material and have the identical cantilever beam architectures; moreover, the piezoelectric layers and sizes of these are also kept the same. Linear BEH-1 has the tip mass of 36 grams and its resonant frequency is $28.2 \mathrm{~Hz}$; however, in contrast, linear BEH-2 has a resonant frequency of $80.4 \mathrm{~Hz}$ and has no mass at the tip of the cantilever beam. With the nonlinear BEH-3, one magnet is attached to the tip mass and the other is fixed near to moving magnet in repulsive configuration. The excitation of the bridge is simulated with the vibration shaker in order to characterize (at $10 \mathrm{k} \Omega$ load resistance) the developed BEHs. The $\mathrm{BEHs}$ are tested for the bridge's vibration at the entrance, mid span, and exit. At the entrance and mid span, the performance of BEH-3 is reported to be better than the other energy harvesters. A maximum voltage of $0.64 \mathrm{~V}$ and power of $41.1 \mu \mathrm{W}$ are produced by BEH-3 at the bridge's entrance $(0.364 \mathrm{~g})$; however, at the mid span $(0.27 \mathrm{~g})$, it generated a voltage of $0.46 \mathrm{~V}$ and a power of $21.3 \mu \mathrm{W}$. However, at the bridge's exit $(0.157 \mathrm{~g}), \mathrm{BEH}-1$ is reported to perform well and an optimum voltage of $0.31 \mathrm{~V}$ and a power of $9.7 \mu \mathrm{W}$ are reported for this linear BEH-1.

An energy harvester for the train-induced vibration in bridge structure is reported in [62]. Finite element modeling is used to predict the bridge's excitation and power production from the piezoelectric BEH (located at the underside bridge's surface) for various types of trains. It is reported that the power production BEH with PZT as transduction material is much better than that of PVDF (power generation is $52 \%$ of PZT). The developed BEHs are tested on a singlespan, composite (steel-concrete) bridge $(36 \mathrm{~m}$ long and $6.7 \mathrm{~m}$ wide), and at a train's speed of $120 \mathrm{~km} / \mathrm{hr}$, it is reported to generate a maximum power of $1.6 \mu \mathrm{W}$ (with PZT-based harvester) and $0.82 \mu \mathrm{W}$ (with the PVDF-based harvester).

Modeling and simulation for a linear electromagnetic $\mathrm{BEH}$ driven by the lateral vibration (wind induced) of the bridge structure are described in [63]. Two such masstuned BEHs are installed on the bridge's girder and are modeled as single degree of freedom (lumped parameter model) mechanical oscillators. At a wind speed of $30 \mathrm{~m} / \mathrm{s}$, the simulation results predicted a mass displacement of $0.5 \mathrm{~m}$ for the harvester mass, when the $\mathrm{BEH}$ is installed at the mid span of the bridge; moreover, it is reported to produce an optimized power of $2400 \mathrm{~W}$ at the same wind speed.

Lumped parameter model for the bridge and an electromagnetic BEH is utilized for the analytical modeling of the coupled system [64]. Single degree of freedom and two degree of freedom-tuned mass energy harvesters are modeled and simulated for the bridge's excitations. A nondimensional steady state power of 4.8 and 5 is reported for a single and two degree of freedom $\mathrm{BEH}$ at equivalent damping ratio of 0.01 and 2 , respectively.

In this research, work BEHs are developed to power the bridge monitoring system. The work is the extension of the $\mathrm{BEH}$ developed by the authors in [65]. The energy harvesters are capable to produce power simultaneously from the

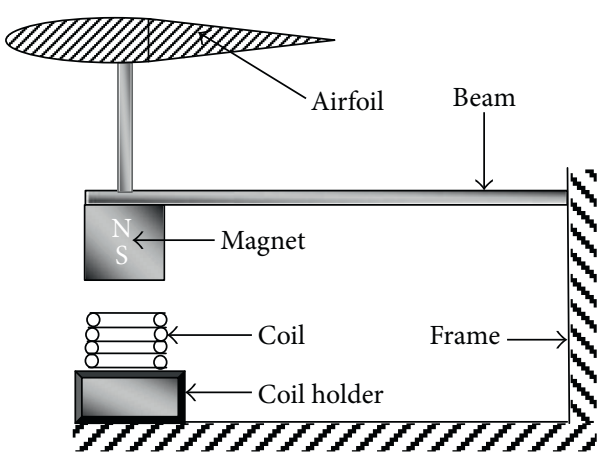

FIGURE 2: Architecture of the bridge energy harvester, prototype I.

vibrations and wind available at bridge's structure. Two low frequency, electromagnetic, cantilever-type, vibration-based and wind-based harvesters, prototype I, and prototype II are produced. For the prototypes, novel device architecture is utilized in which an airfoil is mounted at the free end of the cantilever beam and is used to also extract the wind energy. Moreover, the airfoil and the relevant attachment are also exploited to have an extra device's resonant frequency. Prototype II has dual cantilever beams: one beam contains the magnet; however, the other lower beam has the wound coil. The wound coil beam actually adds an additional resonant frequency to the harvester. Furthermore, most of the reported BEHs are monoresonant and exhibit narrow bandwidth; however, in this work, the multiresonant nature of the developed energy harvesters is exploited to increase the bandwidth of the devices and to harvest the energy from the real narrow band bridge's vibration environment.

\section{Architecture and Working Principle of Prototypes}

The architecture of bridge energy harvester (BEH), prototypes developed in this work, is shown in Figures 2 and 3. The BEHs are comprised of a wound coil, a cylindrical permanent magnet, an airfoil, cantilever beams, and a frame. In BEHs, the magnet and airfoil are attached to the free end of the cantilever beams; however, the wound coils are fixed just underneath the magnets. Moreover, a gap is provided between the magnet and coil to allow free vibration of the magnets over the coils. Prototype I consists of a single beam; however, two cantilever beams are provided in prototype II. The cantilever beam-II, in prototype II, will actually add an extra resonant frequency to the energy harvester. Moreover, a slightly long rod is used with the attached airfoil, in order that the airfoil assembly behaves like an inverted pendulum with a flexible base (beam) and can add another resonant frequency to both the prototypes. The coil holder, in prototype I, can be adjustable in the vertical direction and is used to fix the gap between the magnet and coil according to the level of base vibration. However, in prototype II, provision is provided to move beam-II in vertical direction as well as its length can be adjusted with the help of beam holder slots allowed in the frame. Since prototype II is comprised of two beams, therefore it is capable of extracting the energy from the real random (narrow band) bridge's vibration at both 


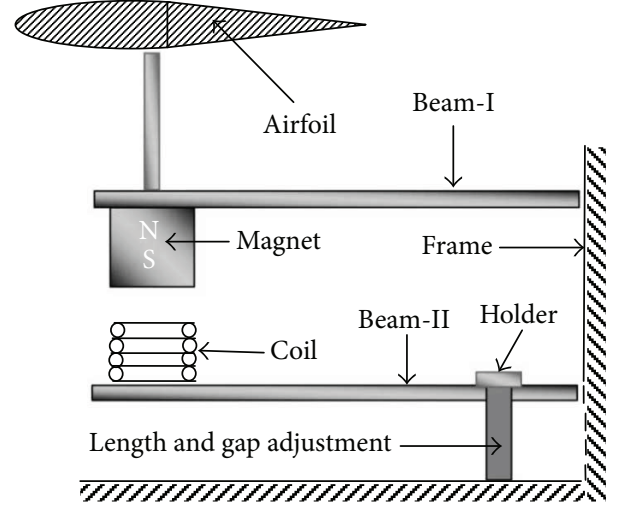

FIGURE 3: Architecture and working principle of prototype II.

resonant frequencies at once. Moreover, in prototype II, the beams are designed stiffer and are more suitable for high acceleration level bridge's vibrations. Furthermore, in accordance to bridge's vibrations, the lower beam in prototype II can easily be tuned to adjust its resonant frequency and alter the bandwidth of the harvester for better performance. When the BEHs are subjected to vibrations, the cantilever beam and the magnet attached to it start oscillation over the coil and as a result of which, a changing magnetic flux density is experienced by the coil and an EMF is induced in the coil according to Faraday's law of electromagnetic induction. Similarly, when the ambient wind surges flow over the airfoil, it produces an upward lift force; however, usually the natural wind flow and even the air surges due to moving traffic are normally fluctuating in nature; therefore, due to these wind surges, the cantilever beam and magnet attached to the airfoil will start oscillating vertically and induce an EMF in the coil. The EMF induced in the coil of the developed BEHs depends on the number of coil turns, magnetic field strength, level of base acceleration, wind speed, and relative velocity between the magnet and the coil.

\section{Modeling of Prototypes}

3.1. Harvester's Beam Design. With lumped parameter model, the undamped fundamental frequency

$$
f_{n}=\frac{1}{2 \pi} \sqrt{\frac{k}{m_{\mathrm{e}}}}
$$

of the cantilever-type energy harvester depends on the beam's stiffness $k$ and equivalent mass $m_{\mathrm{e}}$.

The cantilever beam's stiffness (lumped) [66]

$$
k=\frac{3 E I}{L^{3}}
$$

is a function of beam's length $L$, modulus of elasticity $E$, and moment of inertia [66]

$$
I=\frac{b h^{3}}{12}
$$

of beam's cross-section that depends on the beam's thickness $h$ and width $b$.

The equivalent mass [66]

$$
m_{\mathrm{e}}=\frac{33}{140} m_{\mathrm{b}}+m
$$

of the uniform beam having mass (magnet and airfoil) at the tip can be obtained with beam's mass $m_{\mathrm{b}}$ and tip mass $m$.

Using (1), (2), (3), and (4), the length

$$
L=\left(\frac{35 E b h^{3}}{4 \pi^{2} f_{n}^{2}\left(33 m_{\mathrm{b}}+140 m\right)}\right)^{1 / 3}
$$

of the beam can be obtained in terms of beam's parameters and fundamental frequency.

In order to estimate the beam's length for a certain fundamental frequency (1 to $40 \mathrm{~Hz}$, the targeted frequency range based on bridge vibration data, Table 1) of the $\mathrm{BEH}$ and keeping in view the low frequency operation of the harvesters, the fundamental frequency of $3.6 \mathrm{~Hz}$ and $7.6 \mathrm{~Hz}$ has been selected for the developed prototype I and prototype II, respectively. Moreover, a beam's width and thickness of $4 \mathrm{~cm}$ and $0.4 \mathrm{~mm}$, respectively, are taken for a hot dipped galvanized steel (modulus of elasticity $=E=200 \mathrm{GPa}$ ) beams. The mass (55.6 grams) of the magnet which is to be attached to the beam is measured; however, the mass (30.1 grams) of the airfoil assembly is estimated from the proposed dimensions. Furthermore, the mass of the beam $\left(m_{\mathrm{b}}\right)$ which is supposed to be less in comparison to the tip mass ( $m=85.7$ grams) is ignored during the simulation for the beam's length. Figure 4 shows the simulation result of (5), and for a fundamental frequency of 1 to $40 \mathrm{~Hz}$, the beam's length can be adjusted from $335.7 \mathrm{~mm}$ to $28.7 \mathrm{~mm}$. Moreover, the simulation predicts the beam's length of $142.9 \mathrm{~mm}$ and $86.8 \mathrm{~mm}$ for prototype I and prototype II, respectively.

The beam of cantilever-type energy harvester can also be designed based on the acceleration levels of the bridge's vibrations. By modeling the harvester as single degree of freedom system, the amplitude of the relative displacement [66]

$$
Z=\frac{A\left(\omega / \omega_{\mathrm{n}}\right)^{2}}{\omega^{2} \sqrt{\left[1-\left(\omega / \omega_{\mathrm{n}}\right)^{2}\right]^{2}+\left[2 \xi_{\mathrm{T}}\left(\omega / \omega_{\mathrm{n}}\right)\right]^{2}}}
$$

between the magnet and coil depends on the base acceleration's amplitude $A$, total damping ratio $\xi_{\mathrm{T}}$, undamped natural frequency $\omega_{\mathrm{n}}$, and frequency of base excitation $\omega$.

At resonance, the relative displacement amplitude

$$
Z=\frac{A}{2 \omega_{\mathrm{n}}^{2} \xi_{\mathrm{T}}}
$$

can be used to write the undamped natural frequency

$$
\omega_{\mathrm{n}}^{2}=\frac{A}{2 \xi_{\mathrm{T}} Z}=\frac{k}{m_{\mathrm{e}}}
$$

in terms of base acceleration $A$. 


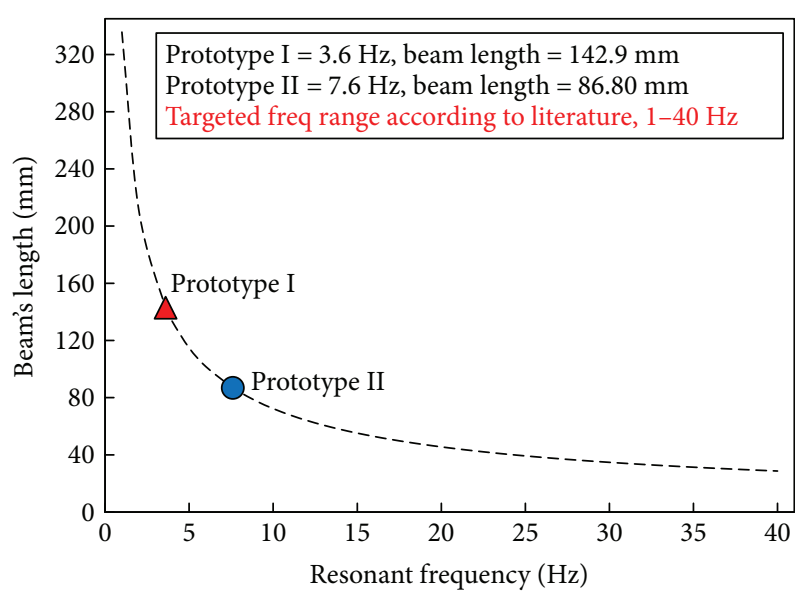

FIGURE 4: Beam's length as a function of the fundamental frequency of the BEH.

By utilizing (2), (3), and (8), the length

$$
L=\left(\frac{\xi_{\mathrm{T}} Z E b h^{3}}{2 A m_{\mathrm{e}}}\right)^{1 / 3}
$$

of the cantilever beam can be expressed in energy harvester's parameters.

Figure 5 shows the simulation result of (9) for a constant gap between the magnet and coil $(Z=1.5 \mathrm{~cm}$, amplitude of relative displacement). During simulation, the acceleration levels from 0.006 to $0.55 \mathrm{~g}$ (bridges' vibration data, Table 1) are utilized to predict the length of hot dipped galvanized steel (modulus of elasticity $=E=200 \mathrm{GPa}$ ) beam with a width and thickness of $4 \mathrm{~cm}$ and $0.4 \mathrm{~mm}$, respectively, and having a tip mass of 85.7 grams (mass of magnet and airfoil assembly). Moreover, the total damping ratio from 0.0001 to 0.025 is used for the simulation purpose. For high acceleration level vibrations, the stiffness of the harvester's beam needs to be also on higher side; however, to operate effectively in low acceleration vibration environment, the beam is required to be less stiff and the same is revealed by the simulation in Figure 5. As per acceleration level, the length of the beam is required to be adjusted, and long beam will be suitable for low acceleration vibration; however, for high acceleration vibration, the beam's length is kept to be short. Moreover, at a specific acceleration level, the beam's length also depends on the total damping ratio, while for harvesters with high damping, relatively long beams have to be adopted. At ultralower acceleration levels from $0.0006 \mathrm{~g}$ to $0.031 \mathrm{~g}$, the reduction in beam's length is about $41.5 \%$ irrespective of the total damping ratio of the harvester. A percentage reduction of 31.6 in the beam's length occurs for an acceleration range from $0.032 \mathrm{~g}$ to $0.1 \mathrm{~g}$. However, for relatively high acceleration levels from $0.102 \mathrm{~g}$ to $0.55 \mathrm{~g}$, the beam's length has to be reduced by $43 \%$.

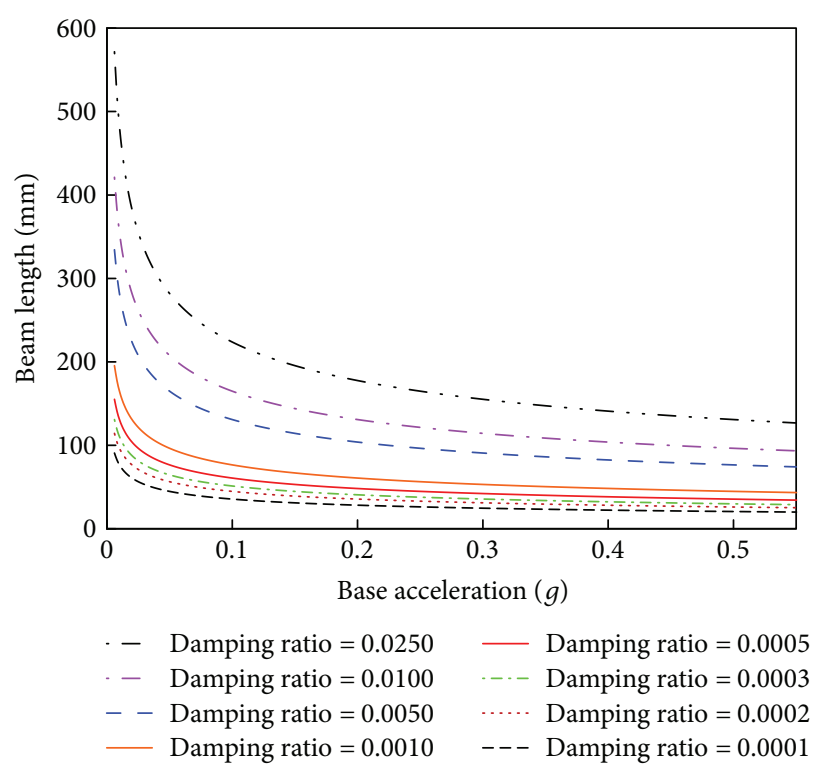

FIgURE 5: Harvester's beam length as a function of the bridge's base acceleration at different total damping ratios.

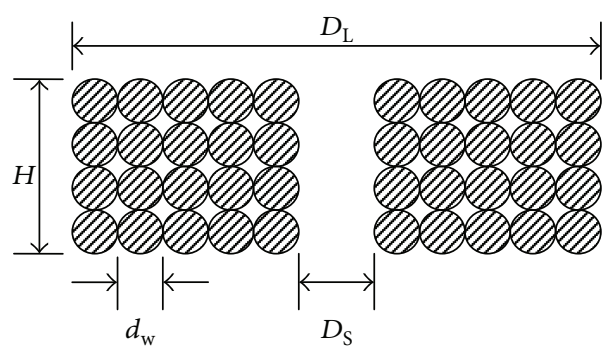

FIgURE 6: Cross-section of a wound coil of energy harvester.

3.2. Harvester's Wound Coil Design. For a wound coil (Figure 6) in an electromagnetic energy harvester, the number of turns

$$
n=\frac{D_{\mathrm{L}}-D_{\mathrm{S}}}{2 d_{\mathrm{w}}}
$$

in each layer and the number layers

$$
N_{1}=\frac{H}{d_{\mathrm{w}}}
$$

in wound coil depend on coil's outer diameter $D_{\mathrm{L}}$, inner diameter $D_{\mathrm{S}}$, height $H$, and wire diameter $d_{\mathrm{w}}$ and can be used to compute the total number of coil turns

$$
N_{\mathrm{t}}=n N_{\mathrm{l}}=\frac{H}{d_{\mathrm{w}}}\left(\frac{D_{\mathrm{L}}-D_{\mathrm{S}}}{2 d_{\mathrm{w}}}\right) \text {. }
$$

In electromagnetic energy harvesters, the coil's resistance

$$
R_{\mathrm{C}}=\frac{\rho_{\mathrm{c}} L_{\mathrm{t}}}{A_{\mathrm{c}}}=\frac{4 \rho_{\mathrm{c}} N_{\mathrm{l}} L_{\mathrm{l}}}{\pi d_{\mathrm{w}}^{2}}=\frac{\rho_{\mathrm{c}} H L_{\mathrm{l}}}{\pi d_{\mathrm{w}}^{3}}=\frac{\rho_{\mathrm{c}} H}{d_{\mathrm{w}}^{3}} \sum_{i=1}^{n}\left[D_{\mathrm{S}}+(2 i-1) d_{\mathrm{w}}\right]
$$




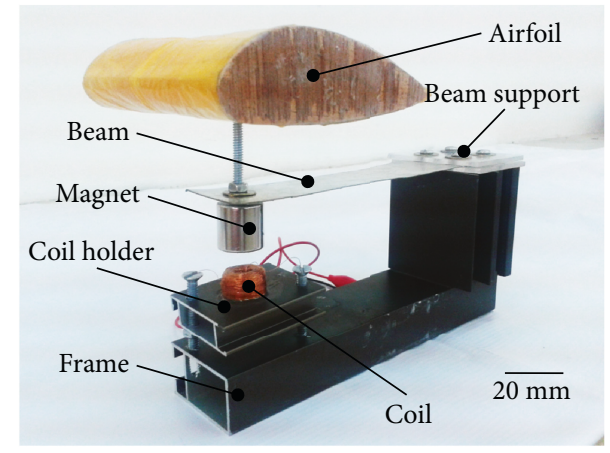

FIGURE 7: Photograph of the fabricated BEH, prototype I.

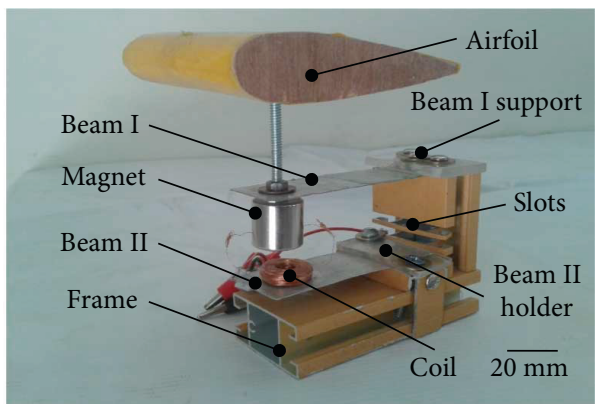

FIgURE 8: Photograph of the fabricated BEH, prototype II.

that is also the function of the coil's material and coil's parameters (dimensions) is important, since the optimum load is normally equal to the coil's resistance for mesoscale coils [45]. There are two ways to manufacture the wound coil in an electromagnetic BEH. By using the coil's dimensions as constraints, (12) can be utilized to compute the total number of coil's turns; however, by producing coil in this way has the disadvantage that the coil resistance is not a constraint.

However, by utilizing (13), the coil's resistance can also be kept as a constraint along the other coil's parameters and the number of coil's turns can be adjusted such that (13) is satisfied.

\section{Fabrication of Prototypes}

The developed BEHs, prototype I and prototype II, are shown in Figures 7 and 8. The base support (frame) of the $\mathrm{BEH}$ are produced from commercially available aluminum sections (Forward Metals, UK). The cantilever beams holding the neodymium $(\mathrm{NdFeB})$ magnets are fabricated from a galvanized steel sheet (Shanghai Metal Co., China). By using a manual winding apparatus, a wound coil is made from an enameled copper wire of $80 \mu \mathrm{m}$ diameter. In prototype I, the produced wound coil has a thickness of $10 \mathrm{~mm}$ and diameter of $18 \mathrm{~mm}$ and contains 965 turns. However, a coil of $4 \mathrm{~mm}$ thickness and $20 \mathrm{~mm}$ diameter and having 400 turns is formed for prototype II. Moreover, for the prototypes, the airfoils are fabricated from a light weight Thermophore insulation sheet (Industrial Enterprises, Pakistan) and plywood. The fabricated airfoils are then attached to the free end of cantilever beams through a long bolt and a nut. A cylindrical permanent magnet is then attached to the bottom
TABLE 2: Main features and dimensions of developed BEHs.

\begin{tabular}{lcc}
\hline Feature & Prototype I & Prototype II \\
\hline Coil's resistance & $54.5 \Omega$ & $28 \Omega$ \\
Magnetic flux & $1.32 \mathrm{~T}$ & $1.32 \mathrm{~T}$ \\
density & $55.6 \mathrm{grams}$ & 55.6 grams \\
Magnet's mass & $1.5 \mathrm{~cm}$ & $20 \mathrm{~mm} \times 20 \mathrm{~mm}$ \\
Magnet's dimensions & $965 \times 20 \mathrm{~mm}$ & $1 \mathrm{~cm}$ \\
Coil and magnet gap & $4 \mathrm{~cm}$ & 400 \\
Number of coil turns & - & $3 \mathrm{~cm}$ \\
Width of beam-I & $0.40 \mathrm{~mm}$ & $2.9 \mathrm{~cm}$ \\
Width of beam-II & $14 \mathrm{~cm}$ & $0.40 \mathrm{~mm}$ \\
Thickness of beam-I & - & $8 \mathrm{~cm}$ \\
Length of beam-I & - & $0.30 \mathrm{~mm}$ \\
Thickness of beam-II & - & $5.7 \mathrm{~cm}$ \\
Length of beam-II & $10 \mathrm{~cm} \times 10 \mathrm{~cm} \times 3 \mathrm{~cm}$ & $8.5 \mathrm{~cm} \times 8 \mathrm{~cm} \times 2 \mathrm{~cm}$ \\
Airfoil dimensions & $8 \mathrm{~cm} \times 6 \mathrm{~cm} \times 4 \mathrm{~cm}$ \\
Device overall size & $14 \mathrm{~cm} \times 9 \mathrm{~cm} \times 5 \mathrm{~cm}$ & 8
\end{tabular}

side of the top cantilever beam. Just underneath the magnet, the wound coil, in prototype I, is bonded to the coil's holder located at the harvester's base and in prototype II, the coil is glued to the bottom cantilever beam-II. The coil holder of prototype I can move up and down with the help of screws to adjust the desired gap between the magnet and the coil. However, in prototype II, the beam-II support is kept movable and adjustable. This beam-II support is designed in such a way that with it, not only the magnet-coil gap is adjusted but also the beam holder is moved along the base, and the length of beam-II can be selected in order to tune beam-II accordingly. Furthermore, small size nuts and bolts and screws are utilized to securely clamp and assembled all the produced parts and components of the BEHs. In both prototypes, the gap between the magnet and coil is adjusted such that, these can be operated in low as well as in relatively high acceleration levels and can produce adequate voltage levels. If the gap is kept too small, the harvesters' performance will be better at low acceleration levels; however, at high acceleration levels, the magnet will touch the coil and alter the harvesters' operation. Moreover, for large gaps, the harvesters will generate high output voltage at high acceleration levels; however, minimum or no voltage will be produced when these are subjected to low accelerations. Dimensions and main parameters of the developed BEHs are provided in Table 2.

\section{Experimentation and Results}

5.1. Characterization of Prototypes under Harmonic Vibrations. With the experimental setup shown in Figure 9, the developed $\mathrm{BEH}$ prototypes have been characterized inside the laboratory. The setup composed of a $12 / 24 \mathrm{~V}, \mathrm{DC}$ power supply (Universal Electronics, Pakistan), a power amplifier (Model: RM-AT2900, Rock Mars, United Arab Emirates), oscilloscope (Model: GOS 6112, GW Instek, New Taipei, Taiwan), a function generator (Model: GFG $8020 \mathrm{H}$, GW Instek, New Taipei, Taiwan), digital multimeter (Model: UT81A/B, Uni-Trend Technology, Dongguan, 


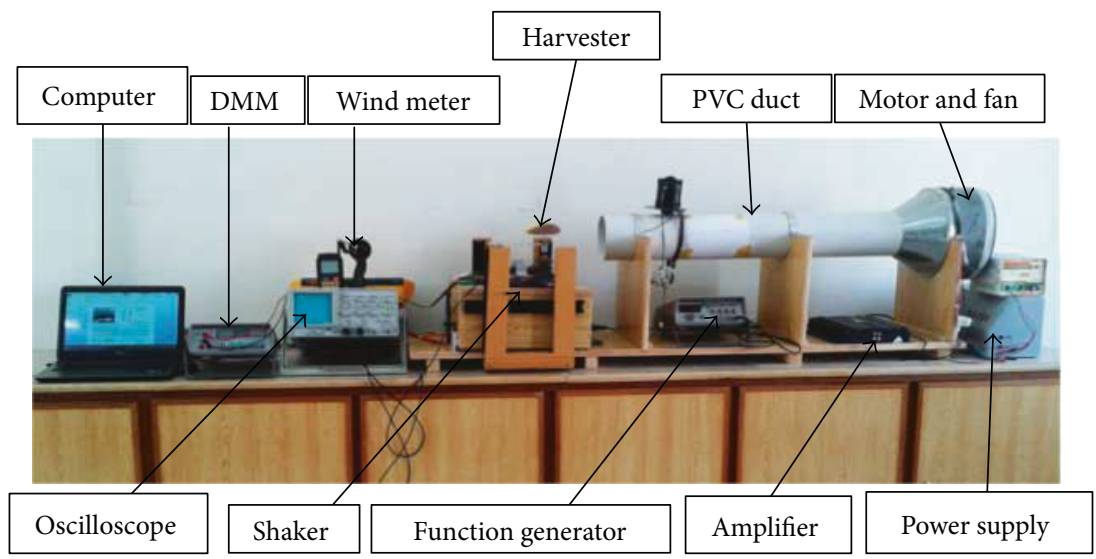

Figure 9: Experimental setup for characterization of BEHs.

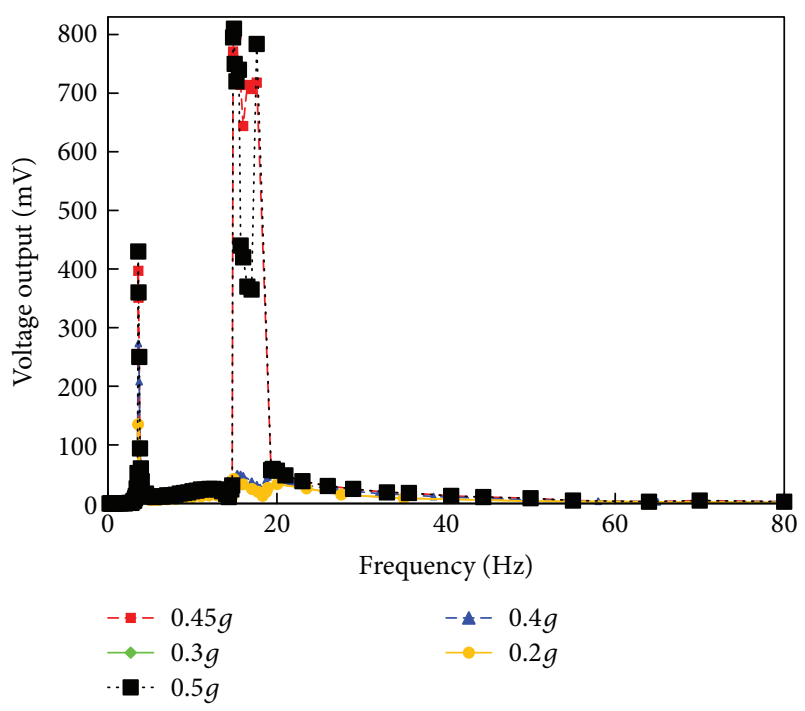

Figure 10: Open circuit RMS voltage produced as a function of frequency for $\mathrm{BEH}$ prototype I.

China), vibration shaker, and an accelerometer (Model: EVAL-ADXL335Z, Norwood, USA). Moreover, a variable speed electrical motor, a fan arrangement, and a PVC duct pipe are used to produce surges (variable speed) of air. In the setup, the function generator is used to generate a sinusoidal voltage signal of a desired frequency which is amplified up by the power amplifier and is then supplied to the vibration shaker. The BEH is mounted on a wooden block which is tightly fixed to the shaker's table, and an accelerometer is also attached to the block in order to monitor the acceleration levels to which the $\mathrm{BEH}$ is subjected. The $\mathrm{BEH}$ output voltage signals and the measurements from the accelerometer are measured and analyzed with the oscilloscope and multimeter.

Figures 10 and 11 show open circuit voltage levels of $\mathrm{BEH}$ with respect to excitation frequency at different acceleration levels. The BEHs are subjected to a forward frequency sweep (FFS) from $0.2 \mathrm{~Hz}$ to $80 \mathrm{~Hz}$ and to acceleration levels from $0.2 \mathrm{~g}$ to $0.6 \mathrm{~g}$. As the acceleration level to which the $\mathrm{BEH}$ s are exposed is increased, the output voltage of these

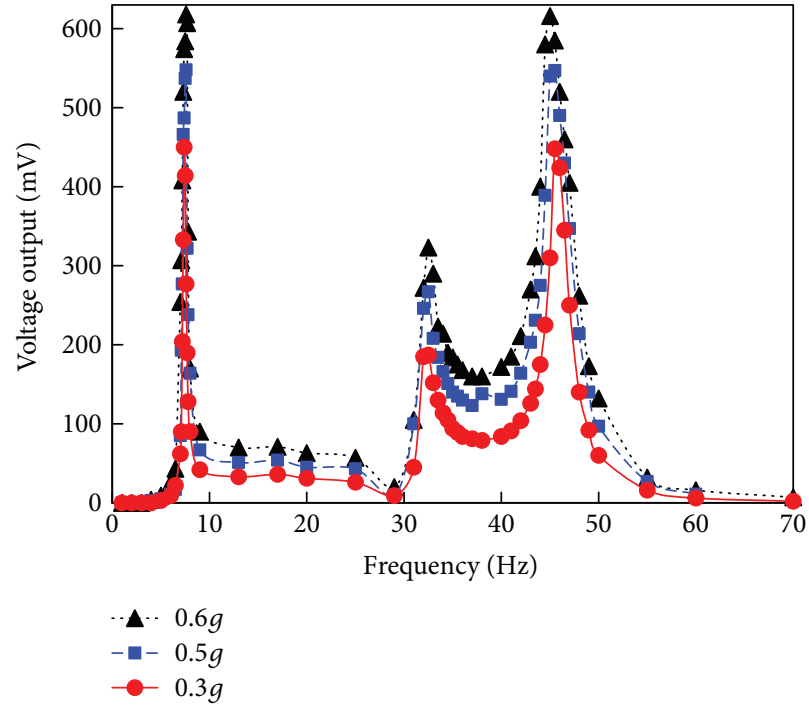

FIGURE 11: Open circuit RMS voltage produced as a function of frequency by $\mathrm{BEH}$ prototype II.

devices also increases. In the tested frequency range, prototype I exhibits three resonant frequencies 3.6 (first resonance of the cantilever beam), 14.9 (resonance of the beam-airfoilmagnet assembly), and $17.6 \mathrm{~Hz}$ (second resonance of the cantilever beam, torsion mode). A maximum voltage of $810 \mathrm{mV}$ is generated at a resonant frequency of $14.9 \mathrm{~Hz}$ and a base excitation of $0.5 \mathrm{~g}$. In prototype $\mathrm{I}$, at a base acceleration greater than $0.5 \mathrm{~g}$, the magnet was touching the coil.

However, under the same testing conditions, the prototype II response is shown in Figure 11. Three resonant frequencies are exhibited by this $\mathrm{BEH}, 7.6 \mathrm{~Hz}$ (first resonance of the upper cantilever beam), $33 \mathrm{~Hz}$ (resonance of the beam-airfoil-magnet assembly), and $45 \mathrm{~Hz}$ (resonant frequency of the second beam upon which the wound coil is placed). At the first resonant frequency in which the magnet along and the upper beam are oscillating, the harvester produces greater output voltage. $\mathrm{BEH}$ prototype II is capable of generating a maximum voltage of $618 \mathrm{mV}$ at a resonant frequency of $7.6 \mathrm{~Hz}$ and at base acceleration of $0.6 \mathrm{~g}$. However, comparatively, less voltage levels are generated at the second 


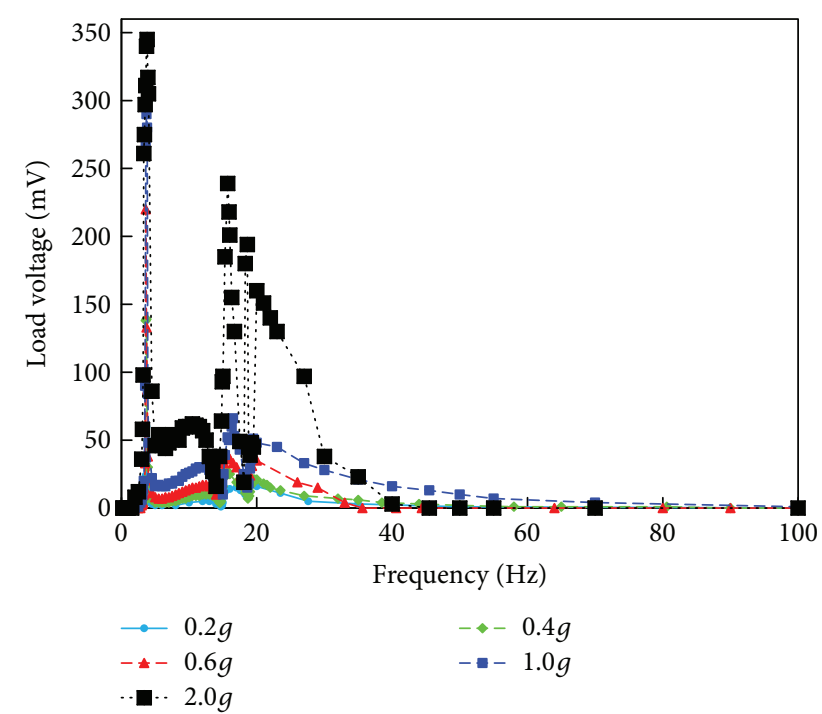

FIgURE 12: Load voltage as function of frequency for prototype I.

resonant frequency; however, at the third resonance of the $\mathrm{BEH}$ prototype II, the voltage production is almost equal to that generated at the first resonant frequency. Since comparatively the beams of prototype II are stiffer, therefore, it is subjected to relatively high acceleration levels (up to $0.6 \mathrm{~g}$ ). The multiresonant behaviour of the prototypes is beneficial and is significant in a number of ways. For example, such characteristic increases the bandwidth of the harvester which is helpful during off resonance operation of the harvesters. The multiresonant prototype performance will be far better than the monoresonant energy harvesters when the operation frequency is slightly away from the resonance; moreover, with multiresonant frequencies, the developed $\mathrm{BEH}$ will be more capable to perform better under the real, narrow band bridge excitations. Since all the resonant frequencies of prototype I are associated with the upper beam only, therefore, it will not be able to harvest the energy from the bridge vibration at all frequencies at once; however, the resonant frequencies of prototype II are not associated with a single beam, therefore, comparatively, during operation, it will be capable to generate power at both beams' resonant frequencies at once.

In Figures 12 and 13, optimum load resistances of $54.5 \Omega$ and $28 \Omega$ are attached to prototype I and prototype II, respectively, and these are subjected to FFS at various acceleration levels. When connected to the optimum load, prototype I produced a maximum RMS load voltage of $345 \mathrm{mV}$ at the resonant frequency of $3.6 \mathrm{~Hz}$ and at a base acceleration of $2 \mathrm{~g}$. On the other hand, prototype II produced a maximum RMS load voltage of $256 \mathrm{mV}$ at a resonant frequency of $7.6 \mathrm{~Hz}$ and at base acceleration of $0.6 \mathrm{~g}$.

In Figures 14, 15, and 16, output load voltage from prototype I with respect to load resistance is depicted. In this experimentation, the $\mathrm{BEH}$ is excited at a resonant frequency of $3.6 \mathrm{~Hz}, 14.9 \mathrm{~Hz}$, and $17.6 \mathrm{~Hz}$ and is subjected to acceleration levels of $0.2,0.3$, and $0.4 \mathrm{~g}$. Different load resistances were connected with the harvester, and output voltage of the prototype is measured. It is obvious from these figures

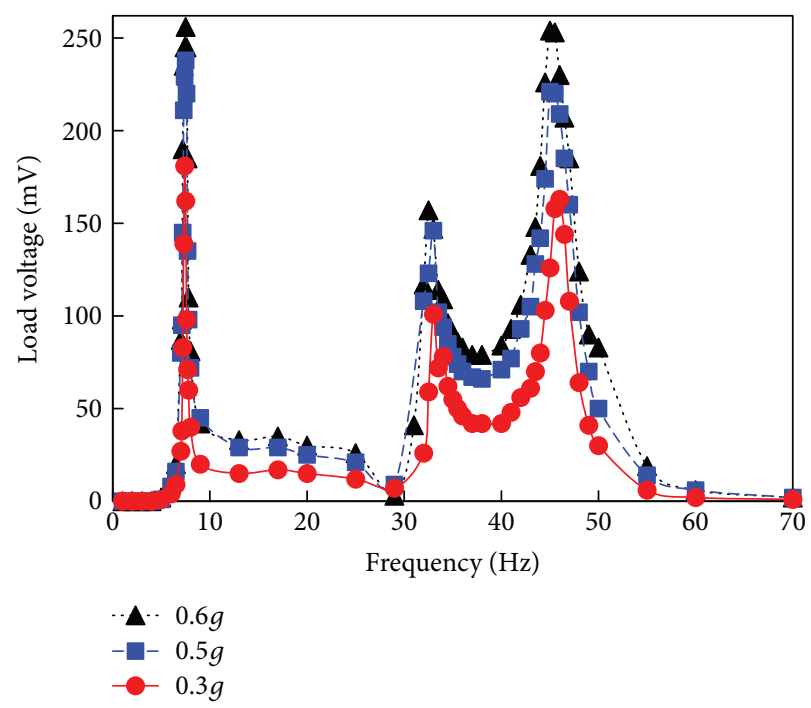

FIGURE 13: Load voltage as a function of frequency for prototype II.

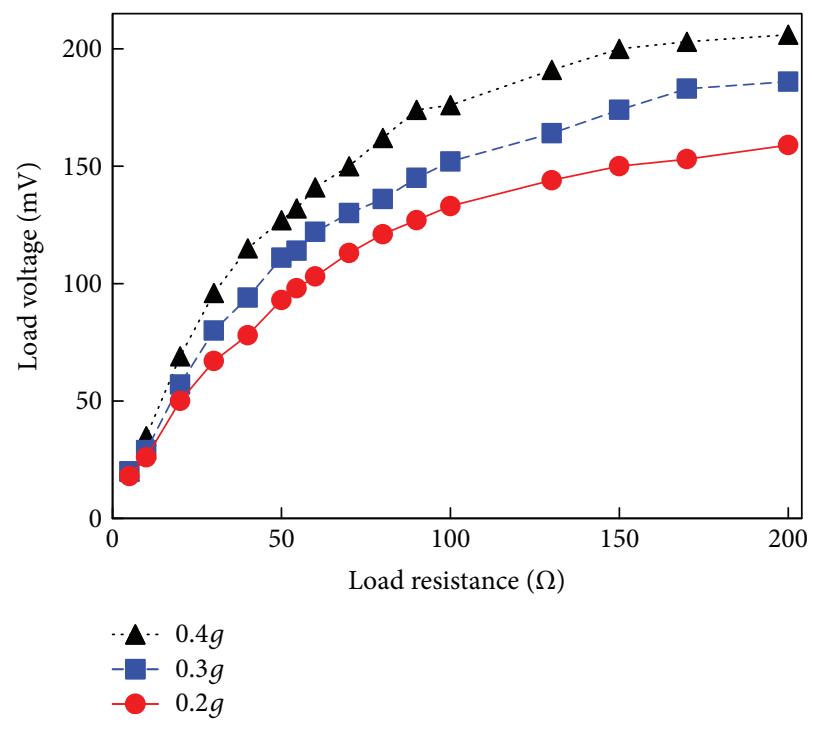

FIGURE 14: Load voltage with respect to load resistance at different $g$ levels and at a resonant frequency of $3.6 \mathrm{~Hz}$ for prototype I.

that, at greater load resistance, high load voltage levels are produced which are attributed to the low current that is flowing in the load. Furthermore, the load voltage is increased as the acceleration level to which the harvester is exposed is increased. At a base acceleration of $0.4 \mathrm{~g}$ and load resistance of $200 \Omega$, maximum load voltage levels of $206 \mathrm{mV}, 58 \mathrm{mV}$, and $25 \mathrm{mV}$ are produced by the harvester when excited at a resonant frequency of $3.6 \mathrm{~Hz}, 14.9 \mathrm{~Hz}$, and $17.6 \mathrm{~Hz}$, respectively.

At the first, second, and third resonant frequencies of $7.6,33$, and $45 \mathrm{~Hz}$, the output load voltage from the BEH prototype II with respect to load resistance is depicted in Figures 17, 18, and 19. The harvester is excited at $0.3 g$, $0.5 \mathrm{~g}$, and $0.6 \mathrm{~g}$ acceleration levels and is characterized for a load resistance from 10 to $100 \Omega$. While attached to $100 \Omega$ load, maximum load voltage levels of $430 \mathrm{mV}, 250 \mathrm{mV}$, and 


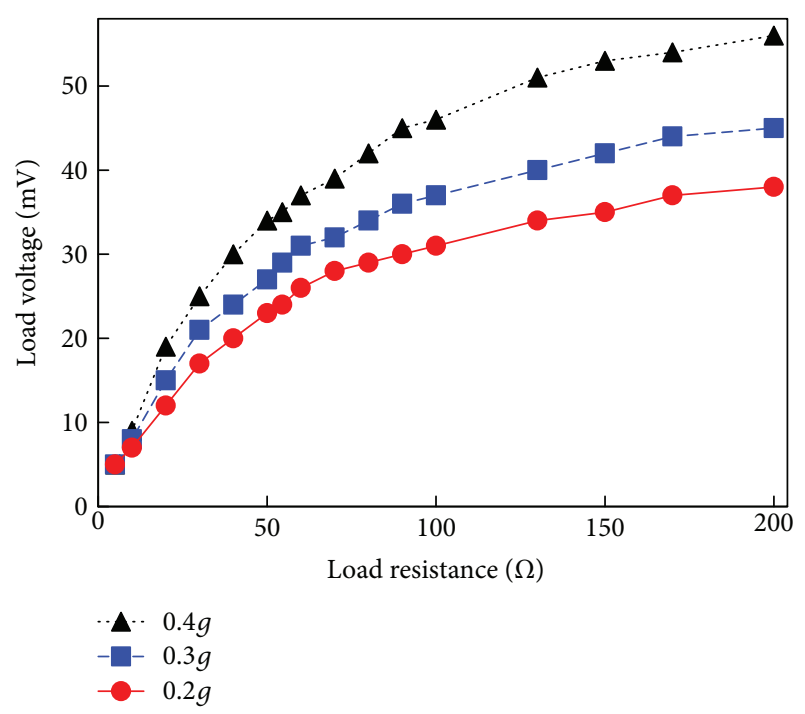

FIGURE 15: Load voltage versus load resistance at different $g$ levels and at $14.9 \mathrm{~Hz}$ resonant frequency for prototype I.

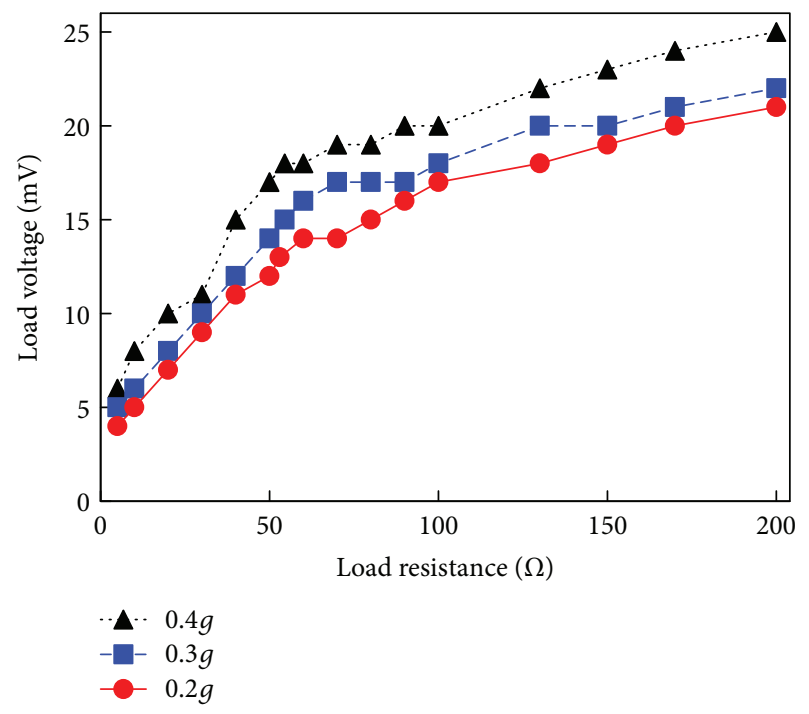

FIGURE 16: Load voltage against load resistance at different $g$ levels and at $17.6 \mathrm{~Hz}$ resonant frequency for prototype I.

$390 \mathrm{mV}$ are produced by the harvester when excited at a base acceleration of $0.6 \mathrm{~g}, 0.5 \mathrm{~g}$, and $0.3 \mathrm{~g}$, respectively.

At the resonant frequencies, the load power characteristics of prototype I as a function of the load resistance are shown in Figures 20, 21, and 22. These figures are obtained with the load voltage data depicted in Figures 15, 16, and 17. The average load power values are computed with the aid of measured load RMS voltage and the corresponding load resistance attached to prototype I. The load power characteristic lines correspond to the device's first $(3.6 \mathrm{~Hz})$, second $(14.9 \mathrm{~Hz})$, and third $(17.6 \mathrm{~Hz})$ resonant frequencies and at base acceleration levels of $0.2,0.3$, and $0.4 \mathrm{~g}$. It is evident from the plots that as the base acceleration level is increased, the more power is generated by the harvester. Relatively, higher power levels are obtained at the first

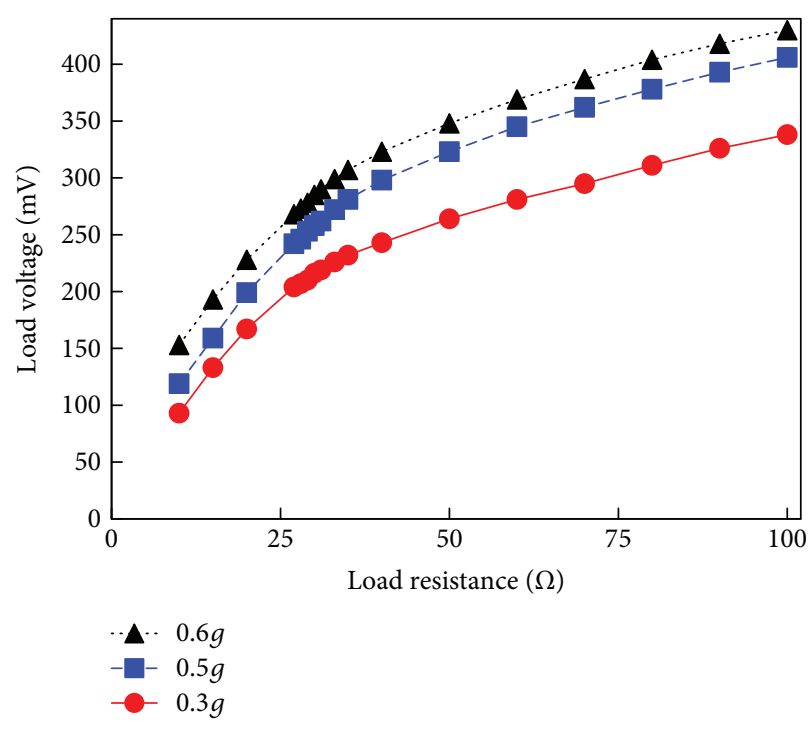

FIGURE 17: Load voltage with respect to load resistance at $7.6 \mathrm{~Hz}$ for prototype II.

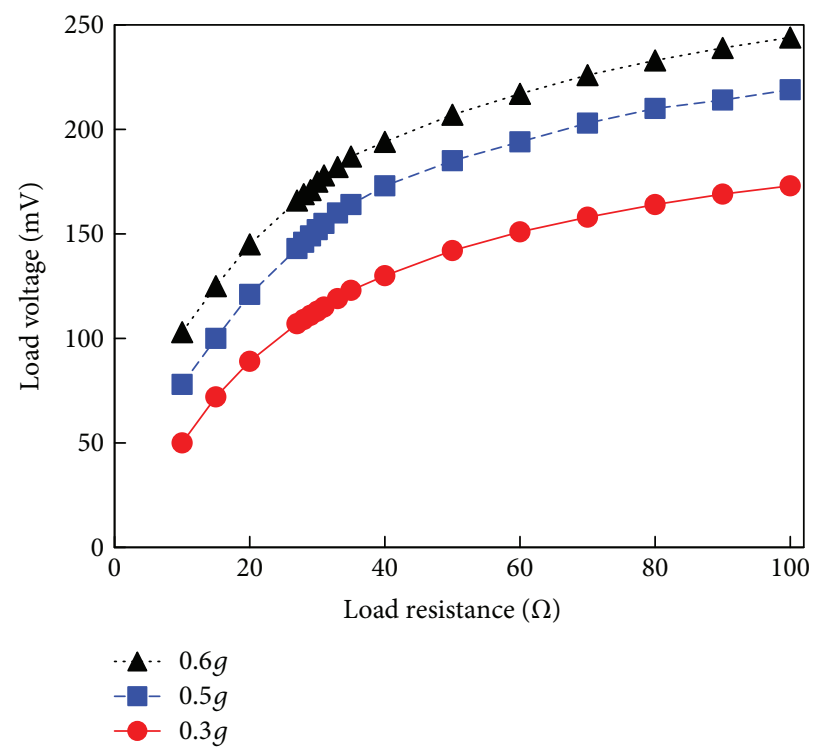

FIGURE 18: Load voltage versus load resistance at different $g$ levels and at $33 \mathrm{~Hz}$ for prototype II.

resonant frequency of $3.6 \mathrm{~Hz}$. Moreover, at all resonant frequencies, the average power delivered to the load is optimum at a condition (maximum power transfer theorem) where the attached load resistance is equal to the coil's resistance $(54.5 \Omega)$. Furthermore, the harvester when excited at $0.4 \mathrm{~g}$ base acceleration level delivered an optimum power of $354.51 \mu \mathrm{W}, 26.5 \mu \mathrm{W}$, and $7.33 \mu \mathrm{W}$ at resonant frequencies of $3.6 \mathrm{~Hz}, 14.9 \mathrm{~Hz}$, and $17.6 \mathrm{~Hz}$, respectively, under optimum load condition.

The BEH prototype II performance in terms of load power (power characteristics) is also analyzed. Figures 23, 24 , and 25 show the average load power produced by the harvester as a function of load resistance at different base accelerations. The device is characterized at three resonant states and under base acceleration levels of $0.3,0.5$, and $0.6 \mathrm{~g}$. The 

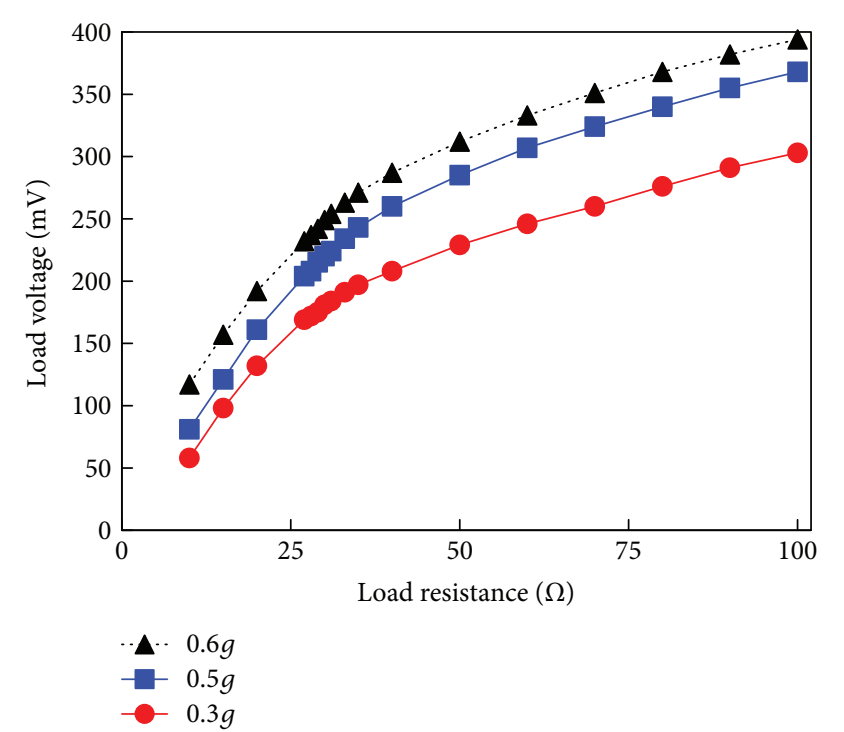

Figure 19: Load voltage against load resistance at $45 \mathrm{~Hz}$ for prototype II.

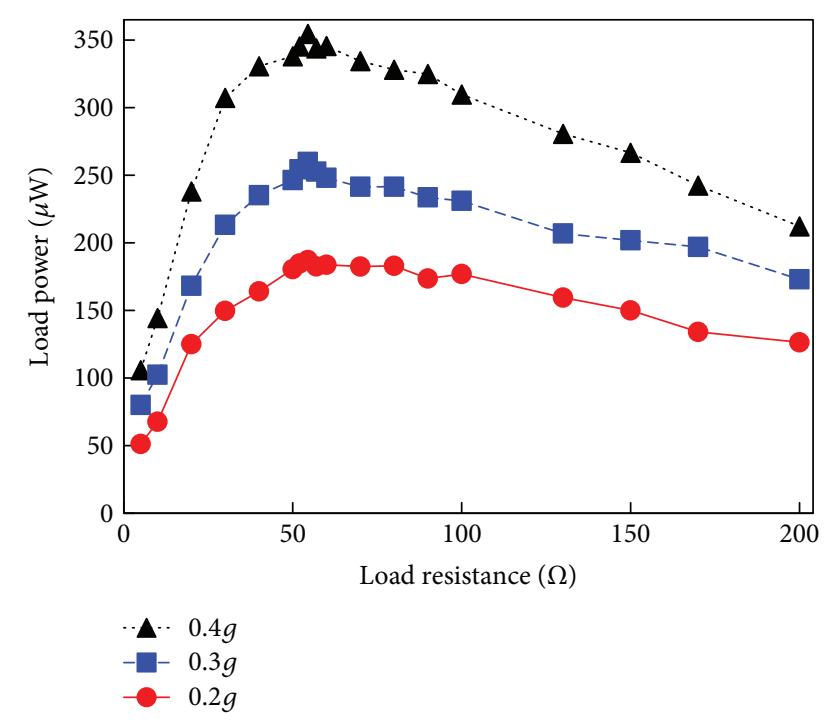

Figure 20: Load Power versus load resistance at different $g$ levels and $3.6 \mathrm{~Hz}$ resonant frequency for prototype $\mathrm{I}$.

measured load RMS voltage levels obtained at the respective load resistance are utilized to compute the corresponding power levels $\left(P=V_{\mathrm{RMS}} / R_{\text {load }}\right)$ delivered to the load. Due to better design, optimized wound coil, optimum magnet-coil gap, and lower coil resistance, comparatively, higher power levels are obtained from prototype II. At optimal load resistance of $28 \Omega$ (resistance of the coil), maximum power levels of $2214.32 \mu \mathrm{W}, 836.03 \mu \mathrm{W}$, and $2178.89 \mu \mathrm{W}$ are produced at $0.6 \mathrm{~g}$ acceleration and at resonant frequency of $7.6 \mathrm{~Hz}, 35 \mathrm{~Hz}$, and $45 \mathrm{~Hz}$, respectively.

For a magnet and coil gap of $1.5 \mathrm{~cm}$ (prototype I) and $1 \mathrm{~cm}$ (prototype II), the developed prototypes have been characterized at acceleration levels from 0.2 to $0.6 \mathrm{~g}$. For a constant beam's length, too low acceleration levels will actually result in a very small relative displacement between

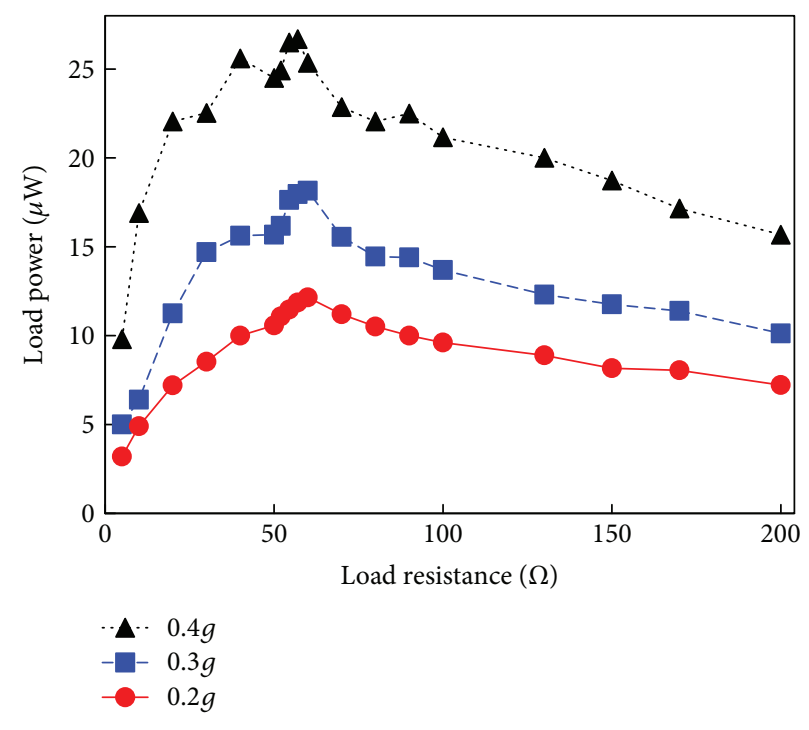

FIgURe 21: Load Power with respect to load resistance at different $g$ levels and $14.9 \mathrm{~Hz}$ resonant frequencies for prototype II.

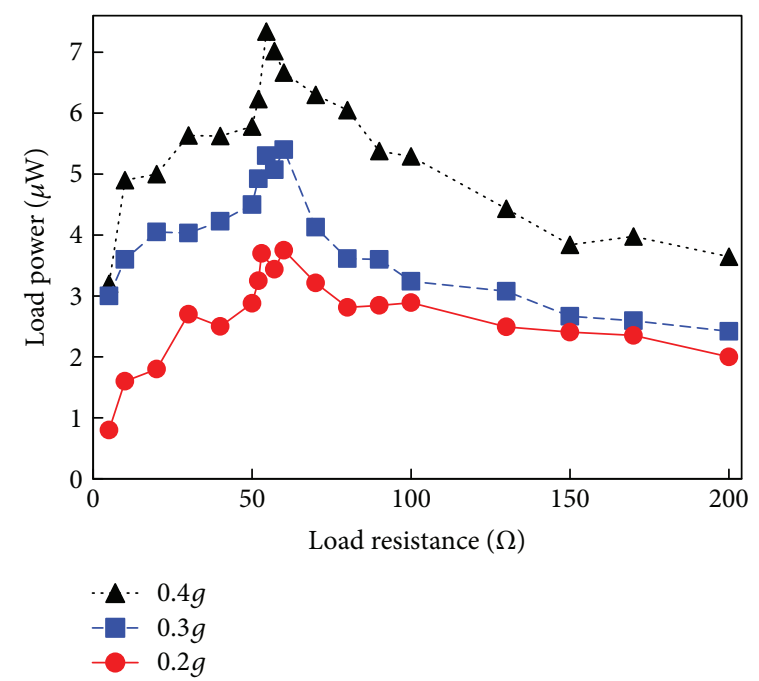

FIgURe 22: Load Power as a function of load resistance at different $g$ levels and $17.6 \mathrm{~Hz}$ resonant frequencies for prototype I.

magnet and coil and hence the performance of the harvesters would be highly affected. If the gap between the coil and magnet is not altered, then in the harvester, the beam's length is required to be modified according to the specific low acceleration of the bridge's vibration. Based on vibration's acceleration level, the harvester's beam length can be adjusted as per simulation performed in Figure 5. For ultralow acceleration levels such as $0.0006 \mathrm{~g}$, the beams' length needs to be from $90.7 \mathrm{~mm}$ to $571.5 \mathrm{~mm}$ for the total damping ratio of 0.0001 and 0.025 , respectively. However, for relatively high acceleration levels, like $0.03 \mathrm{~g}$, for the total damping ratio of 0.0001 and 0.025 , the beams' length is required to be kept from $53 \mathrm{~mm}$ to $334.2 \mathrm{~mm}$, respectively, for better operation. Moreover, for the same values of total damping ratio's and at a bridge's acceleration level of $0.1 \mathrm{~g}$, the beam's lengths of $35.5 \mathrm{~mm}$ and $223.7 \mathrm{~mm}$, respectively, will be highly effective for the harvester's efficient operation. 


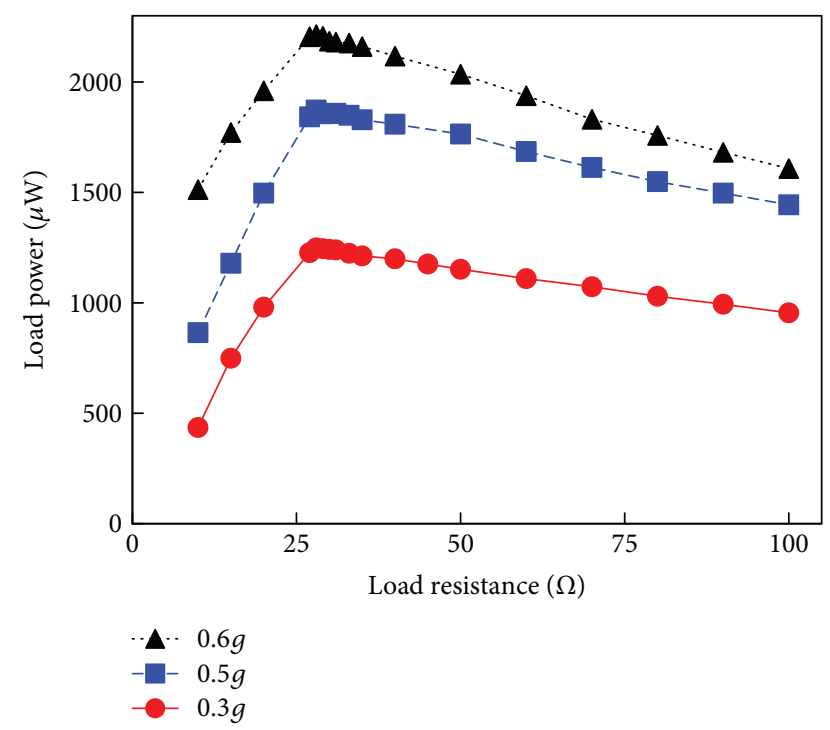

FIGURE 23: Load power as function of load resistance at $7.6 \mathrm{~Hz}$ for prototype II.

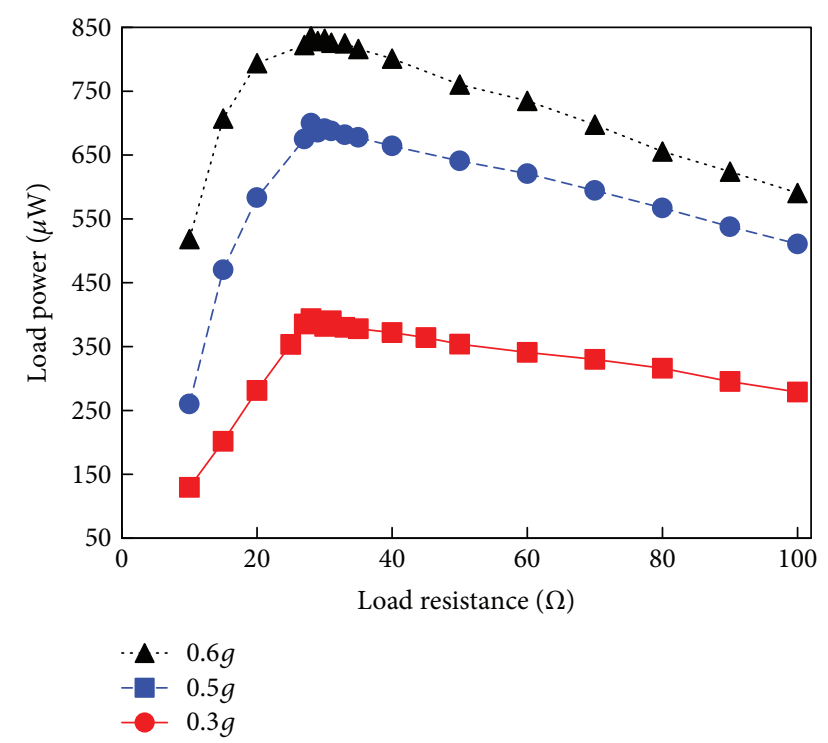

FIGURE 24: Load power with respect to load resistance at $35 \mathrm{~Hz}$ for prototype II.

However, in the developed prototypes, the provision of the gap adjustment is provided and with simple modification, these can be very easily utilized to operate efficiently and effectively under ultralow and low bridge's vibration. In the prototypes for the existing beams, the gap between the magnet and coil can be minimized (optimized) to significantly extract the energy from the ultralow and low levels of acceleration.

\subsection{Characterization of BEH Prototypes under High Speed Air} Surges. The harvesters are also characterized in the scenario of ambient high speed wind. In the testing rig, the wind blowing setup is utilized to perform experiments on energy harvesters. Figures 26 and 27 show the open circuit and load

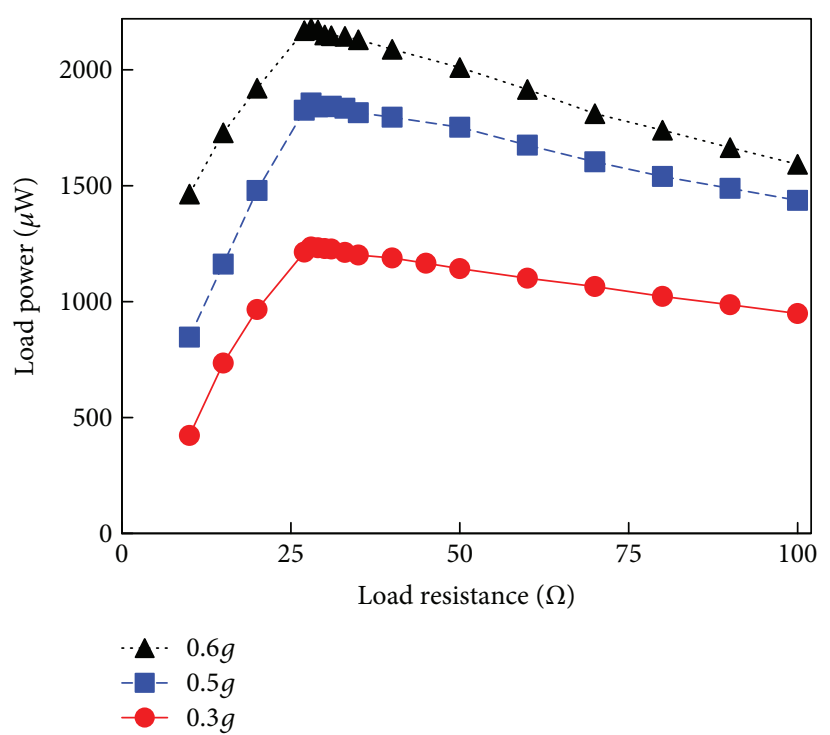

Figure 25: Load power as a function of load resistance at $45 \mathrm{~Hz}$ for prototype II.

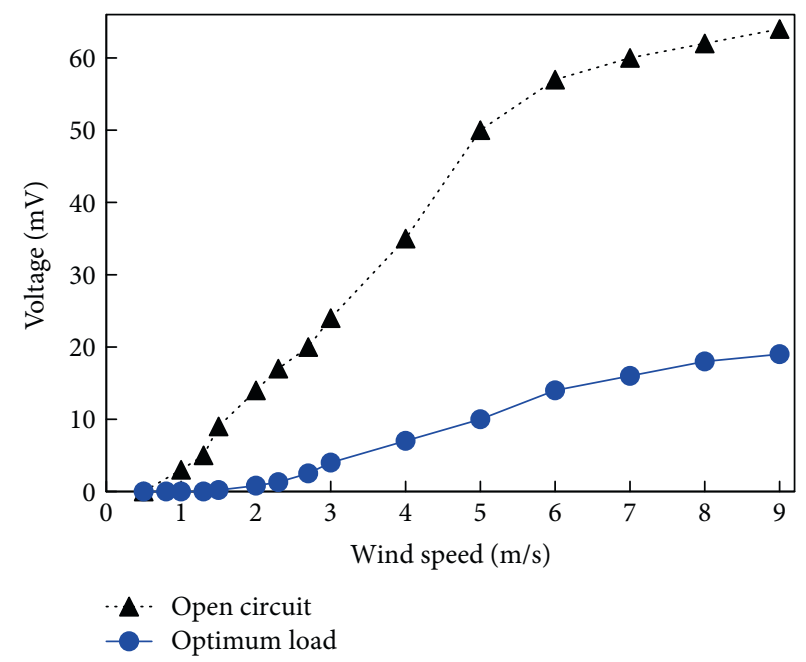

Figure 26: Generated voltage as a function of wind speed for prototype I.

voltage levels generated by prototype I and prototype II as a function of wind speed. In the measurements, the air speed is gradually increased by regulating the fan rotation and voltage levels are recorded at various air speeds. Moreover, for measuring the wind speed, a flow anemometer (Model AR856, Intell Instruments ${ }^{\mathrm{TM}}$ Plus, China) is used. Prototype I is characterized for an air speed from $0.5 \mathrm{~m} / \mathrm{s}$ to $9 \mathrm{~m} / \mathrm{s}$. It is clear from the graph that as the wind speed to which the harvesters are subjected is increased, the output voltage level increases. For prototype I, a maximum open circuit voltage of $64 \mathrm{mV}$ and a load voltage of $19 \mathrm{mV}$ (at optimum load resistance of $54.5 \Omega$ ) are produced at an air flow of $9 \mathrm{~m} / \mathrm{s}$. However, the performance of prototype II is determined under an air speed from 0.5 to $6 \mathrm{~m} / \mathrm{s}$. In prototype II, at an air speed higher than $6 \mathrm{~m} / \mathrm{s}$, the magnet was touching the coil; therefore, it was not subjected to air speed beyond $6 \mathrm{~m} / \mathrm{s}$. For prototype II, a maximum open circuit output voltage $(84 \mathrm{mV})$ is obtained at an 


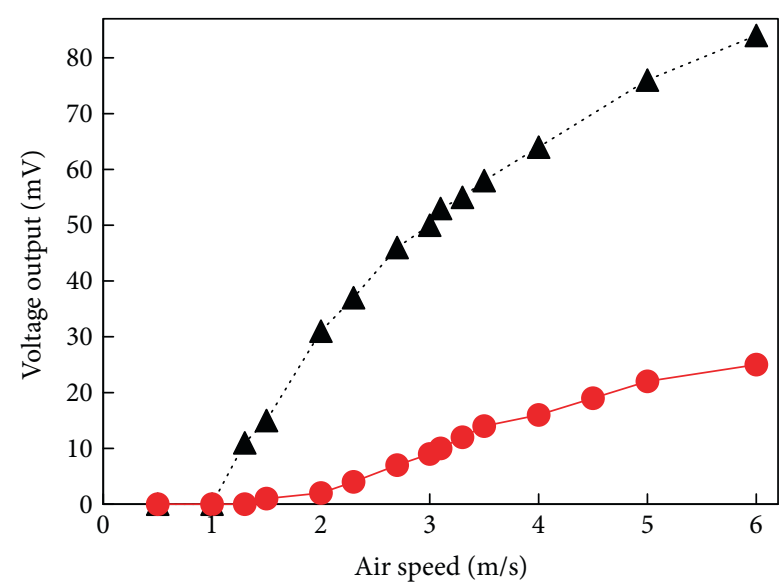

- Open circuit

- Optimum load

FIGURE 27: Voltage as a function of wind speed graph for prototype II.

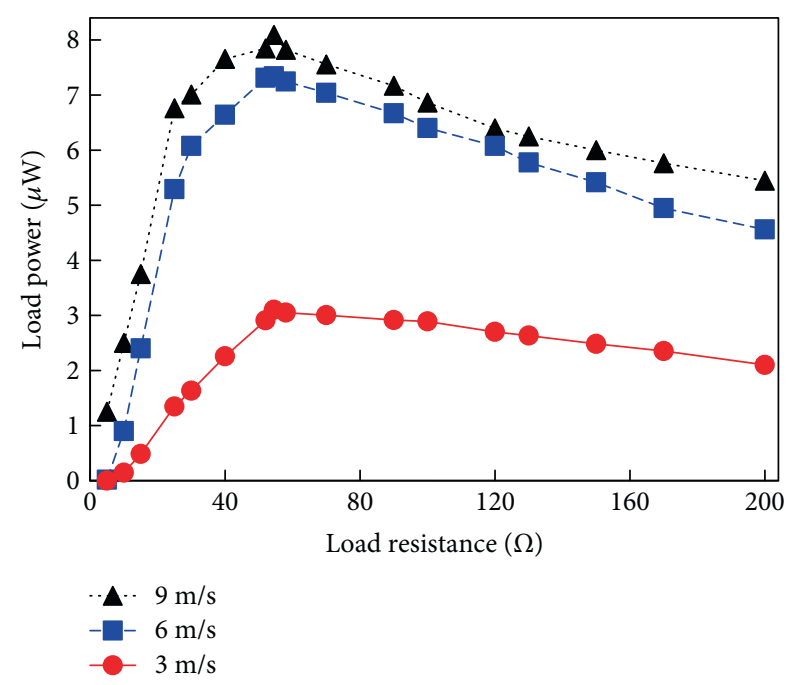

Figure 28: Load power with respect to load resistance at different wind speed for prototype I.

applied wind speed of $6 \mathrm{~m} / \mathrm{s}$. However, under load condition, when $28 \Omega$ (optimum load) is attached to the harvester, a maximum load voltage of $22 \mathrm{mV}$ is delivered. Just as under vibration testing, prototype II seems to produce high voltage levels than prototype I, when it is subjected to variable air speed flow.

Figures 28 and 29 show the output power generated by prototype I and prototype II as a function of load resistance at different wind speeds. In this experiment, prototype $I$ is subjected to specific air speed $(3,6$, and $9 \mathrm{~m} / \mathrm{s})$ and various load resistances are connected to the harvester and load voltage levels are measured. The recorded load voltage values are used to compute the corresponding power levels delivered to the load. It is clear from Figure 28 that at $9 \mathrm{~m} / \mathrm{s}$ air speed, a maximum load power of $7.84 \mu \mathrm{W}$ is obtained from prototype I, when connected to a load resistance of $54.5 \Omega$ (identical to coil resistance). Moreover, under optimum load condition,

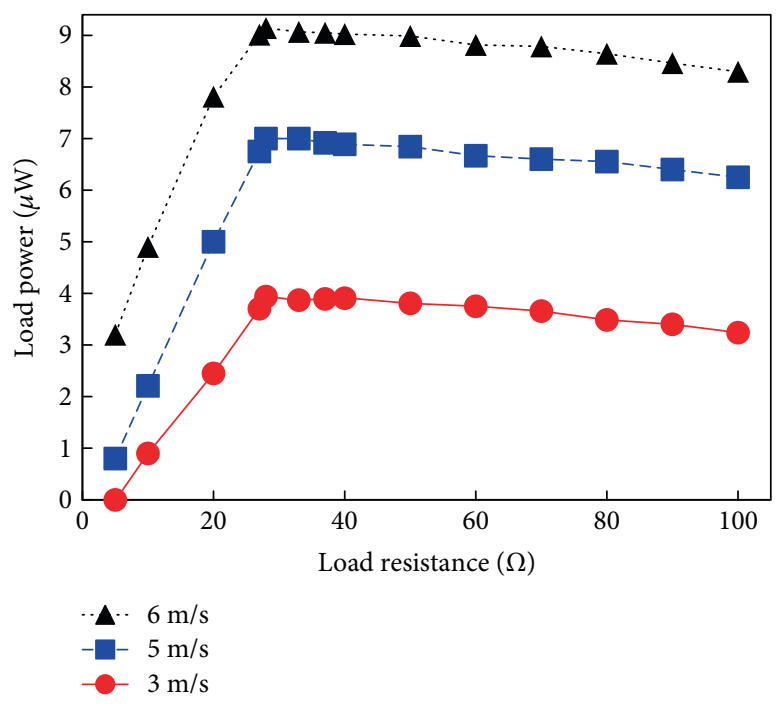

FIGURE 29: Load power with respect to load resistance at different wind speed for prototype II.

the harvester produced optimum power levels of $3 \mu \mathrm{W}$ and $7.1 \mu \mathrm{W}$ at $3 \mathrm{~m} / \mathrm{s}$ and $6 \mathrm{~m} / \mathrm{s}$ wind speed, respectively. However, the optimum power levels (Figure 29) obtained from prototype II while operating under optimum load condition (28 $\Omega$ load resistance) are $9.14 \mu \mathrm{W}, 7 \mu \mathrm{W}$, and $3.9 \mu \mathrm{W}$ at $6 \mathrm{~m} / \mathrm{s}, 5 \mathrm{~m} / \mathrm{s}$ and $3 \mathrm{~m} / \mathrm{s}$ wind speed, respectively. Similar to the operation of under vibration, prototype II showed the capability of generating more power than prototype I also when these are excited by variable speed air surges.

\section{Comparison and Discussions}

The developed BEHs are listed and compared with each other in Table 3. A number of factors can be utilized to compare these BEHs, such as device's energy transduction method, acceleration levels to which these are designed, harvesters' resonant frequency, number of device resonant frequencies, harvester's bandwidth, mechanism internal impedance, voltage, and power level generation. In all of the reported BEHs, either electromagnetic or piezoelectric energy transduction methods are used. Up until now, the electrostatic transduction method is not adopted for the BEHs and most probably it is due to the fact of the requirement of a battery for the initial charging of the harvester during operation. The resonant frequency range for the reported energy harvesters is $1-120 \mathrm{~Hz}$. The overall acceleration levels to which the devised BEHs are subjected during characterization actually range from 0.008 to $0.6 \mathrm{~g}$. Comparatively, the voltage levels produced by the piezoelectric BEHs (350$28000 \mathrm{mV}$ ) are higher than those generated by the electromagnetic BEHs (10-10000 mV). Most of the electromagnetic BEHs are actually developing voltage levels well below $1 \mathrm{~V}$. However, while relating these BEHs on the basis of power production, it is quite clear that the power generation ability of electromagnetic BEHs $(0.7-26000 \mu \mathrm{W})$ is far better than the piezoelectric BEHs $(0.6-7700 \mu \mathrm{W})$, and this advantage of electromagnetic BEHs in reality is attributed to the low internal impedance of electromagnetic BEHs $(3.6-67 \mathrm{k} \Omega$ ). 
TABLE 3: Comparison of energy harvesters.

\begin{tabular}{|c|c|c|c|c|c|c|c|}
\hline Harvester's type & $\begin{array}{l}\text { Transduction } \\
\text { mechanism }\end{array}$ & $\begin{array}{l}\text { Acceleration } \\
(g)\end{array}$ & $\begin{array}{c}\text { Resonant } \\
\text { frequency }(\mathrm{Hz})\end{array}$ & $\begin{array}{c}\text { Impedance } \\
(\Omega)\end{array}$ & $\begin{array}{l}\text { Voltage } \\
(\mathrm{mV})\end{array}$ & $\begin{array}{c}\text { Power } \\
(\mu \mathrm{W})\end{array}$ & Ref. \\
\hline \multirow{22}{*}{$\begin{array}{l}\text { Bridge energy } \\
\text { harvesters }\end{array}$} & \multirow{13}{*}{ Electromagnetic } & 0.55 & 2 & 1.8 & - & 2.3 & {$[26]$} \\
\hline & & 0.08 & 2.2 & - & - & 26000 & {$[25]$} \\
\hline & & 0.38 & 3.1 & $67 \mathrm{k}$ & 10000 & 12500 & {$[41]$} \\
\hline & & 0.008 & 14 & - & 10 & 2 & {$[42]$} \\
\hline & & 0.025 & 4.1 & 290 & 710 & 120 & {$[43]$} \\
\hline & & 1 & 10 & 270 & - & 39.45 & {$[45]$} \\
\hline & & 1 & 10 & 240 & - & 163 & \multirow{3}{*}[44]{} \\
\hline & & 0.05 & 2 & 240 & - & 57 & \\
\hline & & - & $<1$ & - & - & 0.7 & \\
\hline & & 1 & 10 & 0.22 & 0.1 & 13.6 & {$[57]$} \\
\hline & & 3 & 27 & 3.6 & 15.5 & 2.1 & {$[58]$} \\
\hline & & $0.2-0.4$ & $3.6,14.9, \& 17.6$ & 54.5 & 206 & 354.51 & $\begin{array}{l}\text { [This } \\
\text { work] }\end{array}$ \\
\hline & & $0.3-0.6$ & $7.6,33, \& 45$ & 28 & 430 & 2214.32 & $\begin{array}{l}\text { [This } \\
\text { work] }\end{array}$ \\
\hline & \multirow{9}{*}{ Piezoelectric } & 0.1 & 2 & $70 \mathrm{k}$ & - & 64 & {$[25]$} \\
\hline & & 0.02 & $14-15$ & 100 & $1.8-3.6$ & 30 & {$[27]$} \\
\hline & & - & 14.5 & - & 3600 & 30 & {$[46]$} \\
\hline & & 1 & 40 & $10 \mathrm{M}$ & 28000 & 78.4 & {$[47]$} \\
\hline & & 0.29 & $2.71 \& 120$ & $9.7 \mathrm{k}$ & - & 7700 & {$[48]$} \\
\hline & & 0.21 & 117.1 & $11.8 \mathrm{k}$ & 2000 & 197 & \multirow{2}{*}{ [49] } \\
\hline & & 0.21 & 65.2 & $14.9 \mathrm{k}$ & 5000 & 657 & \\
\hline & & - & 1.5 & 480 & 650 & 83.5 & {$[50]$} \\
\hline & & - & 2 & $200 \mathrm{k}$ & - & 0.6 & {$[52]$} \\
\hline \multirow{14}{*}{$\begin{array}{l}\text { Multimode energy } \\
\text { harvesters }\end{array}$} & \multirow{5}{*}{ Electromagnetic } & 0.76 & $369,938, \& 1184$ & 0.8 & 3.2 & 3.2 & {$[67]$} \\
\hline & & 1 & $840,1070, \& 1490$ & 626 & 3.7 & 0.0041 & {$[68]$} \\
\hline & & 50 & $4200-5000$ & 580 & 10 & 0.4 & [69] \\
\hline & & 50 & $3300-3600$ & 580 & 20 & 0.5 & {$[70]$} \\
\hline & & 1 & $368,530, \& 614$ & 264 & 0.043 & 2.6 & {$[71]$} \\
\hline & \multirow{7}{*}{ Piezoelectric } & 0.1 & $10-100$ & $100 \mathrm{k}$ & 1000 & 5 & {$[72]$} \\
\hline & & 0.1 & $17.5 \& 21.7$ & $100 \mathrm{k}$ & 22.5 & 500 & {$[73]$} \\
\hline & & 0.8 & $\begin{array}{c}101.04,108.16, \& \\
134.4\end{array}$ & - & 3100 & - & {$[74]$} \\
\hline & & 0.05 & $387.1,398.2, \& 398.6$ & $1 \mathrm{M}$ & - & 53 & {$[75]$} \\
\hline & & 1 & $14.2 \& 25.4$ & $71 \mathrm{M}$ & 13.2 & 24.5 & {$[76]$} \\
\hline & & - & $32 \& 41.6$ & $100 \mathrm{k}$ & 30500 & 1000 & {$[77]$} \\
\hline & & 0.2 & $71.8,84.5, \& 188.4$ & $2 \mathrm{M}$ & 1000 & 0.136 & {$[78]$} \\
\hline & \multirow{2}{*}{ Hybrid } & 0.1 & $65-95$ & 116 & - & 2160 & {$[79]$} \\
\hline & & 0.2 & $22.8 \& 25.6$ & 240 & - & 4200 & {$[80]$} \\
\hline
\end{tabular}

The internal impedance of piezoelectric BEHs is relatively on higher side (480-10 M $\Omega$ ). The overall power production $(0.6-26000 \mu \mathrm{W})$ of the developed BEHs is fairly enough to operate the WSNs utilized for the health monitoring of bridges.

In comparison, the BEHs, prototype I and prototype II developed in this work, are the only BEHs, those exhibit multiresonant frequencies and therefore are capable of harvesting the energy from relatively wider band of input bridge's vibrations. The relatively broader bandwidth of the developed prototypes and multiresonant frequencies actually ensure better performance for these harvesters during off resonance operation in comparison to monoresonant energy harvesters whose performance drastically degrade when these are operating at off resonance frequencies. Furthermore, in contrast, the developed harvesters will perform far better in narrow band random vibration environments (such as the bridge's vibration). Moreover, the internal impedance of the harvesters reported in this work is lower than all the reported BEHs except [58]. Among electromagnetic BEHs, 
the voltage production of the harvesters [this work] is also adequate, and only the harvesters $[41,43]$ are capable of generating more power than these (due to large number of turns in the coil). As far as power generation is concerned, only the BEHs $[25,41,48]$ have the tendency to produce larger power than the harvesters developed in this work. Furthermore, the $\mathrm{BEHs}$ in this work are the only harvests which have the ability to extract the energy simultaneously from the bridge's vibration and wind surges (natural or traffic induced) and therefore this feature of the developed BEHs makes these exceptional than the other reported BEHs.

Moreover, the developed BEHs are also compared with the reported multimode energy harvesters listed in Table 3. In comparison, the resonant frequencies of multimode energy harvesters are relatively higher than those of the developed BEHs. There are only few multimode energy harvesters $[73,76,77,80]$, for which the resonant frequencies are reported less than $42 \mathrm{~Hz}$. Due to their higher resonant frequencies, most of the multimode energy harvesters are incapable to perform well under bridges' vibration $(1-40 \mathrm{~Hz})$. Moreover, most of the multimode energy harvesters are subjected to the acceleration levels higher than that at which the developed BEHs are characterized. Only multimode energy harvesters $[72,73,75,79]$ are reported to be tested at acceleration levels less than $0.2 \mathrm{~g}$. By comparing with respect to internal impedance, only the multimode energy harvester [67] has lower impedance than that of the developed BEHs. Furthermore, the voltage generation of the BEHs developed in this work is greater than all of the electromagnetic multimode energy harvesters and the piezoelectric multimode energy harvesters reported in [73, 76]. Among the unhybrid multimode energy harvesters, the developed $\mathrm{BEH}$, prototype II, is capable of producing the highest power level $(2214.32 \mu \mathrm{W})$; however, the unhybrid multimode energy harvesters $[73,77]$ are reported to generate power levels higher than the developed $\mathrm{BEH}$, prototype I. Due to dual transduction mechanisms, the performance of the hybrid multimode energy harvesters $[79,80]$ is better and these are the only reported multimode energy harvesters which produce comparable or higher power levels than the developed BEHs.

\section{Conclusions}

Electromagnetic-based bridge energy harvesters (BEHs) have been developed in this work. The reported energy harvesters utilize the available energies on bridge, such as bridge's vibration and ambient wind to produce power for wireless sensor nodes (WSNs) used for monitoring of the bridge structures. To target low frequency excitation environment, two cantilever-type BEHs, prototype I and prototype II, are produced having the resonant frequencies of $3.6 \mathrm{~Hz}$, $14.9 \mathrm{~Hz}$, and $17.6 \mathrm{~Hz}$ and $7.6 \mathrm{~Hz}, 33 \mathrm{~Hz}$, and $45 \mathrm{~Hz}$, respectively. The BEHs are characterized in both vibration and wind environments and have showed the capability to produced satisfactory voltage and power levels.

Prototype I is suitable for narrow band vibration environment having the frequency content from 1 to $18 \mathrm{~Hz}$ and acceleration levels below $0.4 \mathrm{~g}$ and is capable to generate an open circuit voltage of $810 \mathrm{mV}$, maximum RMS voltage of $206 \mathrm{mV}$ (at $200 \Omega$ ), and an optimum power of $354.51 \mu \mathrm{W}$ (at $54.5 \Omega$ ) in such vibration environment. Moreover, it has also shown the ability to produced adequate voltage and power levels (up to $7.84 \mu \mathrm{W}$ ) from wind surges from $0.5 \mathrm{~m} / \mathrm{s}$ to $9 \mathrm{~m} / \mathrm{s}$.

However, on the other hand, prototype II is more appropriate for vibration surroundings with acceleration levels below $0.6 \mathrm{~g}$ and frequency band from 1 to $45 \mathrm{~Hz}$. It can produce an open circuit voltage of $618 \mathrm{mV}$, a maximum RMS voltage of $430 \mathrm{mV}$ (at $100 \Omega$ ), and an optimum load power of $2214.32 \mu \mathrm{W}$ (at $28 \Omega$ ) from such vibration conditions. Furthermore, it is also able to harvest the power (up to $9.14 \mu \mathrm{W}$ ) from ambient wind with speed from $0.5 \mathrm{~m} / \mathrm{s}$ to $6 \mathrm{~m} / \mathrm{s}$.

In comparison to the other reported BEHs, the energy harvesters developed in this work have showed the ability to produce higher voltage and power than most of the reported BEHs. Moreover, the developed BEHs generated enough power levels to operate the ultralow power sensors and are capable to supplement the power of the batteries in WSNs used for the bridge's health monitoring. Furthermore, the developed BEHs are the only harvests which are capable to extort the energy simultaneously from the bridge's vibration and wind surges (natural or traffic induced).

\section{Conflicts of Interest}

The authors declare that there are no conflicts of interest regarding the publication of this paper.

\section{References}

[1] P. C. Chang, A. Flatau, and S. C. Liu, "Review paper: health monitoring of civil infrastructure," Structural Health Monitoring, vol. 2, no. 3, pp. 257-267, 2003.

[2] C. R. Farrar and N. A. J. Lieven, "Damage prognosis: the future of structural health monitoring," Philosophical Transactions of the Royal Society A, vol. 365, no. 1851, pp. 623-632, 2007.

[3] C. B. Williams, A. Pavic, R. S. Crouch, and R. C. Woods, "Feasibility study of vibration-electric generation for bridge vibration sensors," in Proceedings of the 16th International Modal Analysis Conference (1998 IMAC XVI), pp. 11111117, Santa Barbara, CA, USA, 1998.

[4] F. Khan, F. Sassani, and B. Stoeber, "Nonlinear behaviour of membrane type electromagnetic energy harvester under harmonic and random vibrations," Microsystem Technologies, vol. 20, no. 7, pp. 1323-1335, 2014.

[5] F. U. Khan, "Review of non-resonant vibration based energy harvesters for wireless sensor nodes," Journal of Renewable and Sustainable Energy, vol. 8, no. 4, 2016.

[6] F. U. Khan, T. Ali, and K. Jamil, "Development of a low voltage AC to DC converter for meso and micro energy harvesters," Journal of Engineering and Applied Sciences, vol. 34, no. 2, pp. 35-46, 2015.

[7] F. U. Khan and A. Khattak, "Development of a power management circuit for micro-energy harvesters," Journal of Engineering and Applied Sciences, vol. 34, no. 1, pp. 38-48, 2015.

[8] K. V. Selvan and M. S. M. Ali, "Micro-scale energy harvesting devices: review of methodological performances in the last 
decade," Renewable and Sustainable Energy Reviews, vol. 54, pp. 1035-1047, 2016.

[9] F. U. Khan and M. U. Khattak, "Contributed review: recent developments in acoustic energy harvesting for autonomous wireless sensor nodes applications," Review of Scientific Instruments, vol. 87, no. 2, article 021501, 2016.

[10] F. U. Khan and M. U. Qadir, "State-of-the-art in vibrationbased electrostatic energy harvesting," Journal of Micromechanics and Microengineering, vol. 26, no. 10, article 103001, 2016.

[11] G. Zhou, L. Huang, W. Li, and Z. Zhu, "Harvesting ambient environmental energy for wireless sensor networks: a survey," Journal of Sensors, vol. 2014, Article ID 815467, 20 pages, 2014.

[12] M. Zhang and J. Wang, "Experimental study on piezoelectric energy harvesting from vortex-induced vibrations and wake-induced vibrations," Journal of Sensors, vol. 2016, Article ID 2673292, 7 pages, 2016.

[13] F. U. Khan and Izhar, "State of the art in acoustic energy harvesting," Journal of Micromechanics and Microengineering, vol. 25, article 023001, p. 13, 2015.

[14] E. Lattanzi, M. Dromedari, V. Freschi, and A. Bogliolo, "A sub- $\mu$ A ultrasonic wake-up trigger with addressing capability for wireless sensor nodes," ISRN Sensor Networks, vol. 2013, Article ID 720817, 10 pages, 2013.

[15] W. Wang, S. Liu, Q. Wang et al., “The impact of traffic-induced bridge vibration on rapid repairing high-performance concrete for bridge deck pavement repairs," Advances in Materials Science and Engineering, vol. 2014, Article ID 632051, 9 pages, 2014.

[16] N. G. Elvin, N. Lajnef, and A. A. Elvin, "Feasibility of structural monitoring with vibration powered sensors," Smart Materials and Structures, vol. 15, no. 4, pp. 977-986, 2006.

[17] F. U. Khan and I. Ahmad, "Review of energy harvesters utilizing bridge vibrations," Shock and Vibration, vol. 2016, Article ID 1340402, 21 pages, 2016.

[18] S. Priya, "Modeling of electric energy harvesting using piezoelectric windmill," Applied Physics Letters, vol. 87, no. 18, pp. 184101-184103, 2005.

[19] E. Sazonov, H. Li, D. Curry, and P. Pillay, "Self-powered sensors for monitoring of highway bridges," IEEE Sensors Journal, vol. 9, no. 11, pp. 1422-1429, 2009.

[20] D. S. Clair, D. Bibo, V. R. Sennakesavababu, M. F. Daqaq, and G. Li, "A scalable concept for micropower generation using flow-induced self-excited oscillations," Applied Physics Letters, vol. 96, no. 14, pp. 144103-144105, 2010.

[21] A. R. Ortiz, C. Ventura, and S. S. Catacoli, "Sensitivity analysis of the lateral damping of bridges for low levels of vibration," in Conference Proceedings of the Society for Experimental Mechanics Series, pp. 101-110, San Antonio, Texas, USA, 2013.

[22] T. Galchev, J. McCullagh, R. L. Peterson, and K. Najafi, "A vibration harvesting system for bridge health monitoring applications," in Proceedings of PowerMEMS, pp. 179-182, Leuven, Belgium, 2010.

[23] H. Bachmann and W. Ammann, Vibrations in Structures : Induced by Man and Machines, International Association for Bridge and Structural Engineering, Zurich, Switzerland, 3rd edition, 1987.

[24] J. Wiberg, Bridge Monitoring to Allow for Reliable Dynamic FE Modeling: A Case Study of the New Arsta Railway Bridge, 2006, October 2017, https://www.diva-portal.org/smash/get/ diva2:9925/FULLTEXT01.pdf.
[25] F. Neitzel, B. Resnik, S. Weisbrich, and A. Friedrich, "Vibration monitoring of bridges," Reports on Geodesy, vol. 1, no. 90, pp. 331-340, 2011.

[26] T. V. Galchev, J. McCullagh, R. L. Peterson, and K. Najafi, "Harvesting traffic-induced vibrations for structural health monitoring of bridges," Journal of Micromechanics and Microengineering, vol. 21, no. 10, article 104005, 2011.

[27] M. Peigney and D. Siegert, "Piezoelectric energy harvesting from traffic-induced bridge vibrations," Smart Materials and Structures, vol. 22, no. 9, article 095019, 2013.

[28] J. Kala, V. Salajka, and P. Hradil, "Footbridge response on single pedestrian induced vibration analysis," World Academy of Science, Engineering and Technology, vol. 3, no. 2, pp. 744$755,2009$.

[29] L. Zhang, X. Yan, and X. yang, "Vehicle-bridge coupled vibration response study of Huanghe cable-stayed bridge due to multiple vehicles parallel with high speed," in 2010 International Conference on Mechanic Automation and Control Engineering (MACE), pp. 1134-1137, Wuhan, China, June 2010.

[30] A. M. A. Ghaffar and R. H. Scanlan, "Ambient vibration studies of golden gate bridge: I. Suspended structure," Journal of Engineering Mechanics, vol. 111, no. 4, pp. 463-482, 1985.

[31] C. E. Dierks, Design of an Electromagnetic Vibration Energy Harvester for Structural Health Monitoring of Bridges Employing Wireless Sensor Networks, MSc dissertation, Department of mechanical engineering, The University of Texas, Austin, TX, USA, 2011.

[32] M. Zhang, D. Brignac, P. Ajmera, and K. Lian, "A low-frequency vibration-to-electrical energy harvester," in Proceedings Volume 6931, Nanosensors and Microsensors for Bio-Systems 2008, p. 69310S, San Diego, CA, USA, 2008.

[33] T. McEvoy, E. Dierks, J. Weaver et al., "Developing innovative energy harvesting approaches for infrastructure health monitoring systems," in ASME 2011 International Design Engineering Technical Conferences and Computers and Information in Engineering Conference, pp. 325-339, Washington, DC, USA, August 2011.

[34] T. Nagayama, Dynamic Characteristics Identification for an Arch Bridge using Wireless Sensor Networks before and after Seismic Retrofit; the Application to Model UpdatingJune 2017, http://www.pwri.go.jp/eng/ujnr/tc/g/pdf/28/28-10-3_ Nagayama.pdf.

[35] T. Galchev, J. McCullagh, R. L. Peterson, and K. Najafi, "A vibration harvesting system for bridge health monitoring applications," in Proceedings of PowerMEMS 2010, pp. 3-6, Leuven, Belgium, 2010.

[36] B. Jo, Y. Lee, G. Yun, C. Park, and J. Kim, "Vibration-induced energy harvesting for green technology," in Proceedings of the International Conference on Chemical, Environment and Civil Engineering (ICCECE '2012), pp. 167-170, Manila, Philippines, November 2012.

[37] Y. Wang, K. J. Loh, J. P. Lynch, M. Fraser, K. Law, and A. Elgamal, "Vibration monitoring of the Voigt bridge using wired and wireless monitoring systems," in The Proceeding of 4th China-Japan-US Symposium on Structural Control and Monitoring, pp. 1-8, China, October 2006.

[38] R. Torah, P. Glynne-Jones, M. Tudor, T. O’Donnell, S. Roy, and S. Beeby, "Self-powered autonomous wireless sensor node using vibration energy harvesting," Measurement Science and Technology, vol. 19, no. 12, article 125202, 2008. 
[39] J. R. Casas and J. J. Moughty, "Bridge damage detection based on vibration data: past and new developments," Frontiers in Built Environment, vol. 3, 2017.

[40] S.-D. Kwon, J. Park, and K. Law, "Electromagnetic energy harvester with repulsively stacked multilayer magnets for low frequency vibrations," Smart Materials and Structures, vol. 22, no. 5, article 055007, 2013.

[41] F. Khan, B. Stoeber, and F. Sassani, "Modeling of linear micro electromagnetic energy harvesters with nonuniform magnetic field for sinusoidal vibrations," Microsystem Technologies, vol. 21, no. 3, pp. 683-692, 2015.

[42] F. Khan, B. Stoeber, and F. Sassani, "Modeling and simulation of linear and nonlinear MEMS scale electromagnetic energy harvesters for random vibration environments," The Scientific World Journal, vol. 2014, Article ID 742580, 15 pages, 2014.

[43] S. Saadon and O. Sidek, "A review of vibration-based MEMS piezoelectric energy harvesters," Energy Conversion and Management, vol. 52, no. 1, pp. 500-504, 2011.

[44] S. P. Beeby, R. N. Torah, M. J. Tudor et al., "A micro electromagnetic generator for vibration energy harvesting," Journal of Micromechanics and Microengineering, vol. 17, no. 7, pp. 1257-1265, 2007.

[45] F. Khan, F. Sassani, and B. Stoeber, "Copper foil-type vibration-based electromagnetic energy harvester," Journal of Micromechanics and Microengineering, vol. 20, no. 12, article 125006, 2010.

[46] C. Cepnik, R. Lausecker, and U. Wallrabe, "Review on electrodynamic energy harvesters-a classification approach," Micromachines, vol. 4, no. 2, pp. 168-196, 2013.

[47] W. J. Choi, Y. Jeon, J. -. H. Jeong, R. Sood, and S. G. Kim, "Energy harvesting MEMS device based on thin film piezoelectric cantilevers," Journal of Electroceramics, vol. 17, no. 2-4, pp. 543-548, 2006.

[48] P. Basset, D. Galayko, M. Paracha, F. Marty, F. Dudka, and T. Bourouina, "A batch-fabricated and electret-free silicon electrostatic vibration energy harvester," Journal of Micromechanics and Microengineering, vol. 19, no. 11, article 115025, 2009.

[49] S. Adhikari, M. I. Friswell, and D. J. Inman, "Piezoelectric energy harvesting from broadband random vibrations," Smart Materials and Structures, vol. 18, no. 11, p. 115005, 2009.

[50] J. Wang, S. Wen, X. Zhao, M. Zhang, and J. Ran, "Piezoelectric wind energy harvesting from self-excited vibration of square cylinder," Journal of Sensors, vol. 2016, Article ID 2353517, 12 pages, 2016.

[51] F. Khan and Izhar, "Piezoelectric type acoustic energy harvester with a tapered Helmholtz cavity for improved performance," Journal of Renewable and Sustainable Energy, vol. 8, no. 5, article 054701, 2016.

[52] F. U. Khan, "Energy harvesting from the stray electromagnetic field around the electrical power cable for smart grid applications," The Scientific World Journal, vol. 2016, Article ID 3934289, 20 pages, 2016.

[53] F. U. Khan and Izhar, "Hybrid acoustic energy harvesting using combined electromagnetic and piezoelectric conversion," Review of Scientific Instruments, vol. 87, no. 2, article 025003, 2016.

[54] F. Khan and S. Razzaq, "Electrodynamic energy harvester for electrical transformer's temperature monitoring system," Sadhana, vol. 40, no. 7, pp. 2001-2019, 2015.
[55] S. Meninger, J. O. Mur-Miranda, R. Amirtharajah, A. P. Chandrakasan, and J. H. Lang, "Vibration-to-electric energy conversion," IEEE Transactions on Very Large Scale Integration (VLSI) Systems, vol. 9, no. 1, pp. 64-76, 2001.

[56] F. U. Khan and M. Iqbal, "Development of a testing rig for vibration and wind based energy harvesters," Journal of Engineering and Applied Science, vol. 35, no. 2, pp. 101-110, 2016.

[57] T. Galchev, H. Kim, and K. Najafi, "Micro power generator for harvesting low-frequency and nonperiodic vibrations," Journal of Microelectromechanical Systems, vol. 20, no. 4, pp. 852-866, 2011.

[58] F. U. Khan and I. Ahmad, "Vibration-based electromagnetic type energy harvester for bridge monitoring sensor application," in 2014 International Conference on Emerging Technologies (ICET), pp. 125-129, Islamabad, Pakistan, December 2014.

[59] M. Rhimi and N. Lajnef, "Tunable energy harvesting from ambient vibrations in civil structures," Journal of Energy Engineering, vol. 138, no. 4, pp. 185-193, 2012.

[60] J. D. Baldwin, S. Roswurm, J. Nolan, and L. Holliday, Energy Harvesting on Highway Bridges, Final Report FHWA-OK-1101, January 2015, http://www.okladot.state.ok.us/hqdiv/p-rdiv/spr-rip/library/reports/rad_spr2-i2224-fy2010-rpt-finalbaldwin.pdf.

[61] F. Orfei, H. Vocca, and L. Gammaitoni, "Linear and non linear energy harvesting from bridge vibrations," in ASME 28th conference on mechanical vibration and noise, Charlotte, North Carolina, USA, August 2016.

[62] P. Cahill, N. A. N. Nuallain, N. Jackson, A. Mathewson, R. Karoumi, and V. Pakrashi, "Energy harvesting from traininduced response in bridges," Journal of Bridge Engineering, vol. 19, no. 9, article 04014034, 2014.

[63] G. Caruso, G. Chirianni, and G. Vairo, "Energy harvesting from wind-induced bridge vibrations via electromagnetic transduction," Engineering Structures, vol. 115, pp. 118-128, 2016.

[64] K. Takeya, E. Sasaki, and Y. Kobayashi, "Design and parametric study on energy harvesting from bridge vibration using tuned dual-mass damper systems," Journal of Sound and Vibration, vol. 361, pp. 50-65, 2016.

[65] F. U. Khan and M. Iqbal, "Electromagnetic-based bridge energy harvester using traffic- induced bridge's vibrations and ambient wind," in 2016 International Conference on Intelligent Systems Engineering (ICISE), pp. 425-430, Islamabad, Pakistan, January 2016.

[66] W. T. Thomson, Theory of Vibration with Applications, third edition, Prentice Hall, England, 1998.

[67] B. Yang, C. Lee, W. Xiang et al., "Electromagnetic energy harvesting from vibrations of multiple frequencies," Journal of Micromechanics and Microengineering, vol. 19, no. 3, article 035001, 2009.

[68] H. Liu, Y. Qian, and C. Lee, "A multi-frequency vibrationbased MEMS electromagnetic energy harvesting device," Sensors and Actuators A: Physical, vol. 204, pp. 37-43, 2013.

[69] I. Sari, T. Balkan, and H. Kulah, "An electromagnetic micro power generator for wideband environmental vibrations," Sensors and Actuators A: Physical, vol. 145-146, pp. 405413, 2008.

[70] I. Sari, T. Balkan, and H. Kulah, "A wideband electromagnetic micro power generator for wireless microsystems," in 
TRANSDUCERS 2007 - 2007 International Solid-State Sensors, Actuators and Microsystems Conference, pp. 275-278, Lyon, France, June 2007.

[71] H. Liu, T. Chen, L. Sun, and C. Lee, "An electromagnetic MEMS energy harvester array with multiple vibration modes," Micromachines, vol. 6, no. 8, pp. 984-992, 2015.

[72] X. Xiong and S. O. Oyadiji, "Design and experimental study of a multi-modal piezoelectric energy harvester," Journal of Mechanical Science and Technology, vol. 31, no. 1, pp. 5-15, 2017.

[73] D. Saravanos, H. Wu, L. Tang, Y. Yang, and C. K. Soh, "A novel two-degrees-of-freedom piezoelectric energy harvester," Journal of Intelligent Material Systems and Structures, vol. 24, no. 3, pp. 357-368, 2013.

[74] S. Dhote, J. Zu, and Y. Zhu, "A nonlinear multi-mode wideband piezoelectric vibration-based energy harvester using compliant orthoplanar spring," Applied Physics Letters, vol. 106, no. 16, article 163903, 2015.

[75] E. E. Aktakka and K. Najafi, "Three-axis piezoelectric vibration energy harvester," in 2015 28th IEEE International Conference on Micro Electro Mechanical Systems (MEMS), pp. 1141-1144, Estoril, Portugal, January 2015.

[76] Q. Tang and X. Li, "Two-stage wideband energy harvester driven by multimode coupled vibration," IEEE/ASME Transactions on Mechatronics, vol. 20, no. 1, pp. 115-121, 2015.

[77] H. Wang and L. Tang, "Modeling and experiment of bistable two-degree-of-freedom energy harvester with magnetic coupling," Mechanical Systems and Signal Processing, vol. 86, pp. 29-39, 2017.

[78] M. Rezaeisaray, M. El Gowini, D. Sameoto, D. Raboud, and W. Moussa, "Low frequency piezoelectric energy harvesting at multi vibration mode shapes," Sensors and Actuators A: Physical, vol. 228, pp. 104-111, 2015.

[79] H.-y. Wang, L.-h. Tang, Y. Guo, X.-b. Shan, and T. Xie, "A 2DOF hybrid energy harvester based on combined piezoelectric and electromagnetic conversion mechanisms," Journal of Zhejiang University SCIENCE A, vol. 15, no. 9, pp. 711-722, 2014.

[80] Z. Xu, X. Shan, D. Chen, and T. Xie, "A novel tunable multi-frequency hybrid vibration energy harvester using piezoelectric and electromagnetic conversion mechanisms," Applied Sciences, vol. 6, no. 1, p. 10, 2016. 


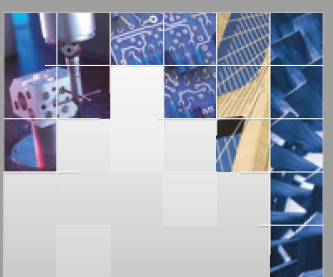

\section{Enfincering}
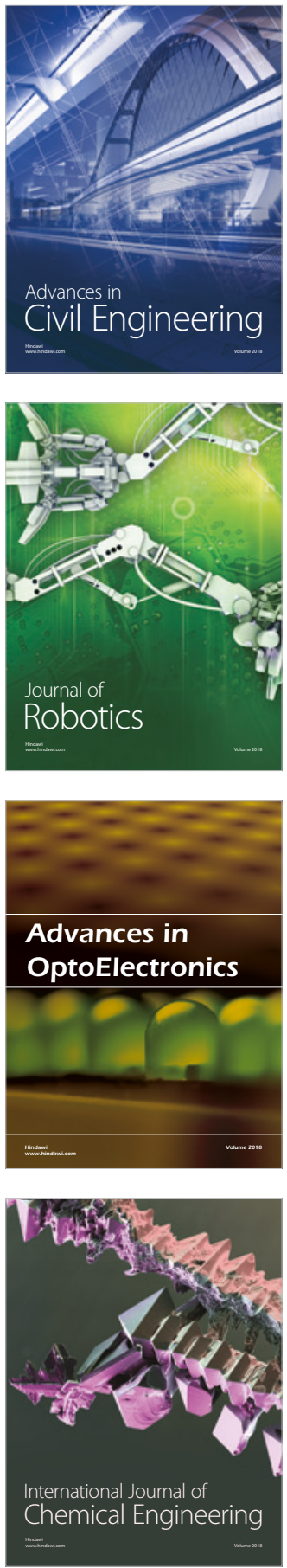

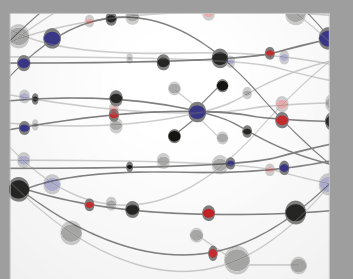

\section{Rotating \\ Machinery}

The Scientific World Journal

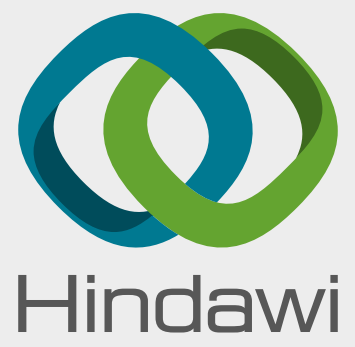

Submit your manuscripts at

www.hindawi.com
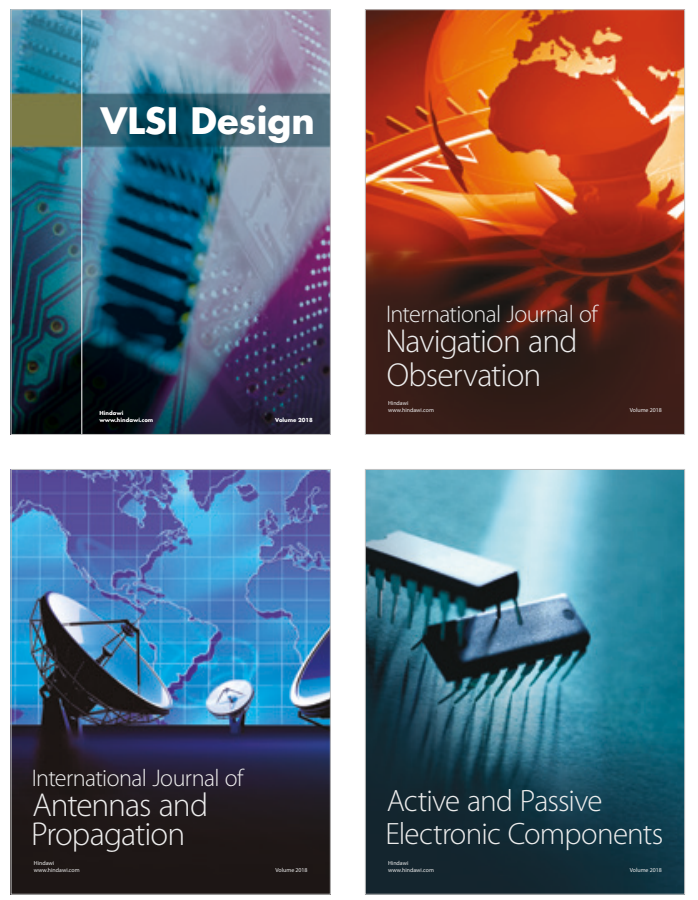
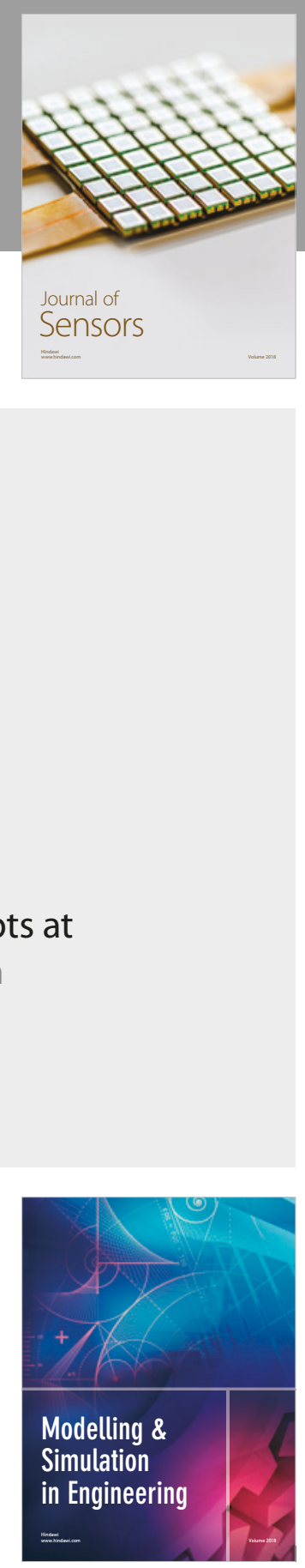

\section{Advances \\ Multimedia}
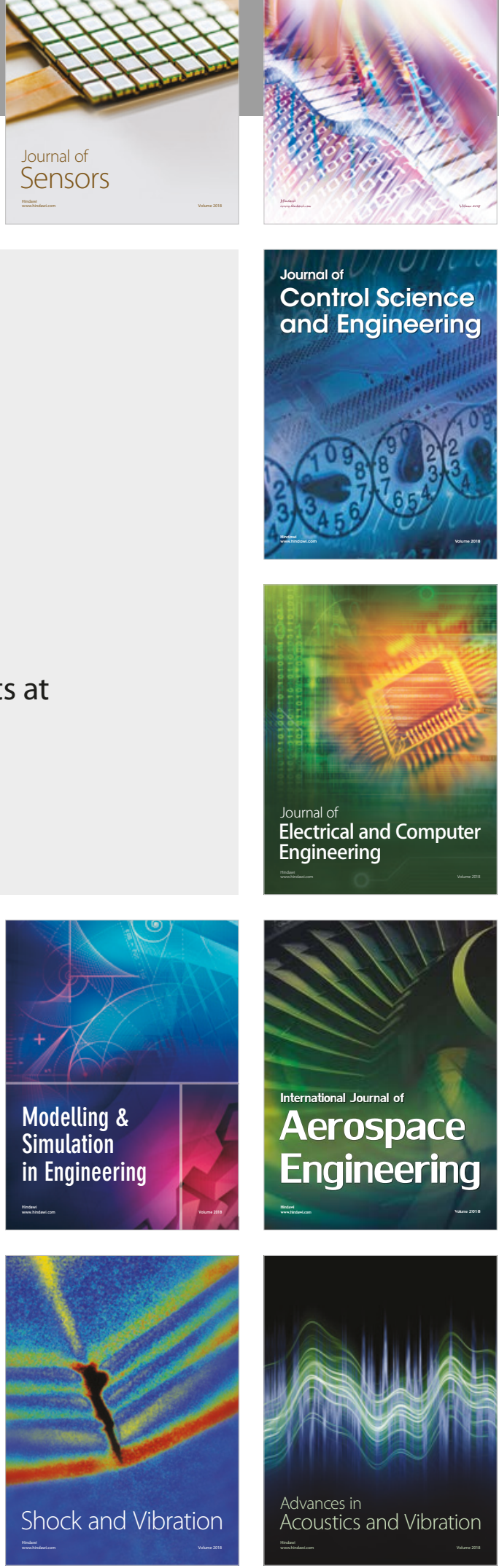